San Jose State University

SJSU ScholarWorks

Master's Theses

Master's Theses and Graduate Research

2007

\title{
Gold nanoparticles patterning using two dimensional protein crystallization
}

Vivian W. $\mathrm{Ng}$

San Jose State University

Follow this and additional works at: https://scholarworks.sjsu.edu/etd_theses

\section{Recommended Citation}

$\mathrm{Ng}$, Vivian W., "Gold nanoparticles patterning using two dimensional protein crystallization" (2007). Master's Theses. 3379.

DOI: https://doi.org/10.31979/etd.j74e-qhqf

https://scholarworks.sjsu.edu/etd_theses/3379

This Thesis is brought to you for free and open access by the Master's Theses and Graduate Research at SJSU ScholarWorks. It has been accepted for inclusion in Master's Theses by an authorized administrator of SJSU ScholarWorks. For more information, please contact scholarworks@sjsu.edu. 
GOLD NANOPARTICLES PATTERNING USING TWO DIMENSIONAL PROTEIN CRYSTALLIZATION

\author{
A Thesis \\ Presented to \\ The Faculty of the Department of Chemical Engineering \\ San Jose State University \\ In Partial Fulfillment \\ of the Requirements for the Degree \\ Masters of Science
}

by

Vivian $\mathrm{W} \mathrm{Ng}$

May 2007 
UMI Number: 1445253

Copyright 2007 by

$\mathrm{Ng}$, Vivian W.

All rights reserved.

\section{INFORMATION TO USERS}

The quality of this reproduction is dependent upon the quality of the copy submitted. Broken or indistinct print, colored or poor quality illustrations and photographs, print bleed-through, substandard margins, and improper alignment can adversely affect reproduction.

In the unlikely event that the author did not send a complete manuscript and there are missing pages, these will be noted. Also, if unauthorized copyright material had to be removed, a note will indicate the deletion.

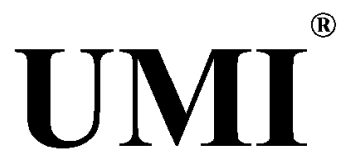

UMI Microform 1445253

Copyright 2007 by ProQuest Information and Learning Company.

All rights reserved. This microform edition is protected against unauthorized copying under Title 17, United States Code.

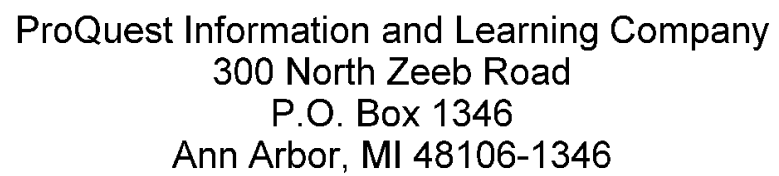


C)2007

Vivian $\mathrm{W} \mathrm{Ng}$

ALL RIGHTS RESERVED 
APPROVED FOR DEPARTMENT OF CHEMICAL ENGINEERING $\frac{M \text { Mhan ma }}{\text { Dr. Melanie McNeil }}$

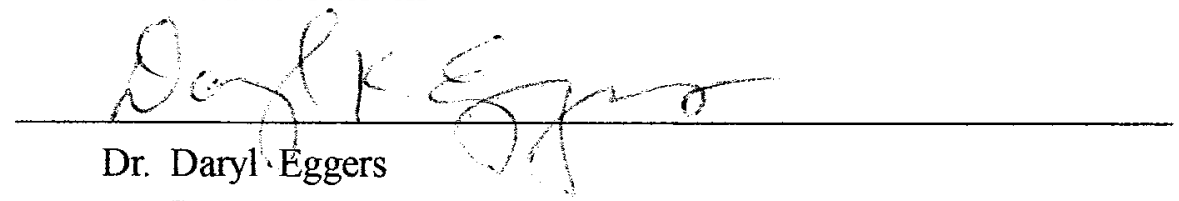

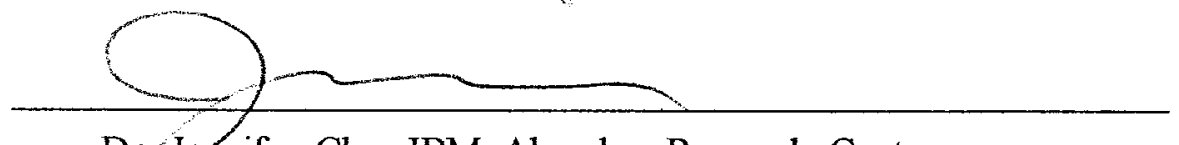

Dr, Jernifer Cha, IBM Almaden Research Center

APPROVED FOR THE UNIVERSITY

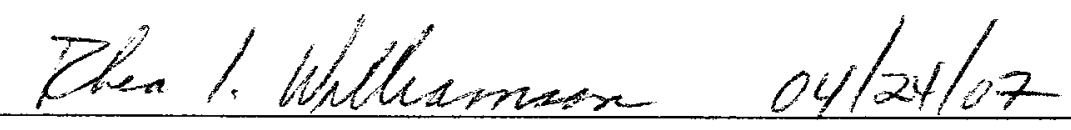




\title{
ABSTRACT \\ GOLD NANOPARTICLES PATTERNING USING TWO DIMENSIONAL PROTEIN CRYSTALLIZATION
}

\author{
by Vivian $\mathrm{W} . \mathrm{Ng}$
}

Nanotechnology has gained a lot of attention since its introduction in the

$1980^{\circ}$ s. The ability to design and produce devices and systems at nanoscale

continues to be of great interest to researchers. In this study, 2D-protein

crystallization was used in place of lithography to generate ordered arrays at the

nanoscale. Experiments using Streptavidin (SAv) conjugated gold nanoparticles ( $\mathrm{Au}$ )

at the air/water interface were performed using a specially designed Teflon block, and

the resulting spacings were captured and measured from TEM images. Differences

in interparticle distances were analyzed using the t-test at $95 \%$ confidence level.

Results showed that the increased number of SAv conjugated to Au associated with

the increase gold nanoparticle interparticle distances for 2SAv-1 Au, but not

ISAv-1Au. Thus, this method can be used to set the interparticle distance whereas

the previous method of using only Au with no SAv attached resulted in a fixed

interparticle distance. 


\section{ACKNOWLEDGEMENTS}

This research was performed at IBM Almaden Research Center in San Jose,

California. I am very grateful to Dr. Jennifer Cha for being able to work with her on this project and for all of her help and advice. I also wish to thank Dr. Melanie McNeil and Dr. Daryl Eggers for their advice on this thesis. Above all, I wish to thank and dedicate this thesis to my parents for their unconditional love and support. 


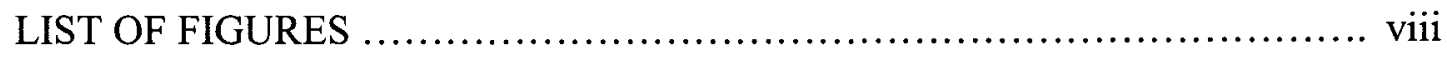

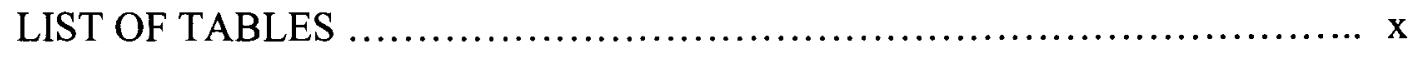

CHAPTER ONE INTRODUCTION ................................. 1

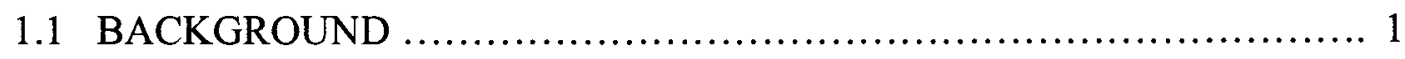

1.2 TWO DIMENSIONAL PROTEIN CRYSTALLIZATION ................ 2

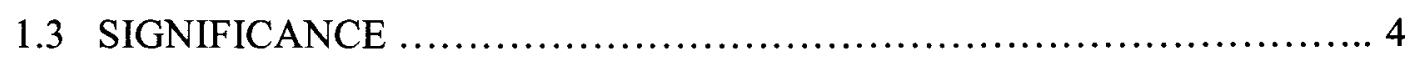

CHAPTER TWO LITERATURE REVIEW ............................. 5

2.1 S-LAYER PROTEIN CRYSTALLIZATION $\ldots \ldots \ldots \ldots \ldots \ldots \ldots \ldots \ldots \ldots$

2.2 CHAPERONIN PROTEIN CRYSTALLIZATION ..........................6

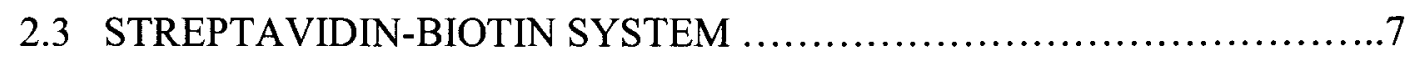

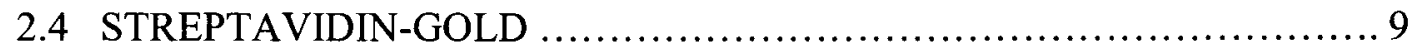

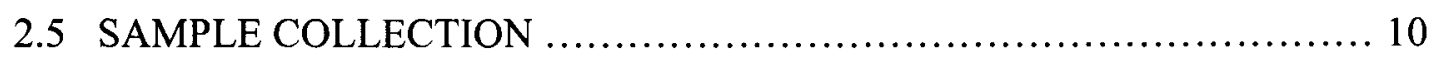

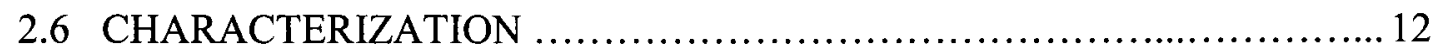

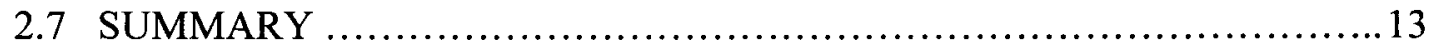

CHAPTER THREE RESEARCH HYPOTHESES ......................... 14

CHAPTER FOUR EXPERIMENTAL DESIGN AND APPAATUS $\ldots \ldots \ldots \ldots \ldots . . \ldots$

4.1 GOLD NANOPARTICLES SYNTHESIS ............................ 16

4.2 GOLD NANOPARTICLES CHARACTERIZATION ...................... 17

4.3 BINDING GOLD NANOPARTICLES WITH STREPTAVIDIN .............17

4.4 GEL ELECTROPHORESIS ........................................ 18

4.5 TWO-DIMENSIONAL PROTEIN CRYSTALLIZATION .................20 
4.6 ANALYTICAL SAMPLE PREPARATION ........................... 22

4.7 TRANSMISSION ELECTRONIC MICROSCOPY (TEM) ................. 23

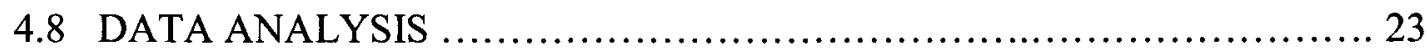

CHAPTER FIVE EXPERIMENTAL RESULTS ........................... 24

5.1 GOLD NANOPARTICLES CHARACTERIZATION .......................24

5.2 BINDING GOLD NANOPARTICLES TO STREPTAVIDIN ...............26

5.3 GEL ELECTROPHORESIS .......................................... 27

5.4 SAV-AU CONJUGATE CHARACTERIZATION ......................... 29

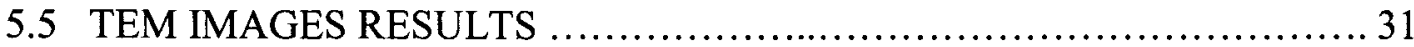

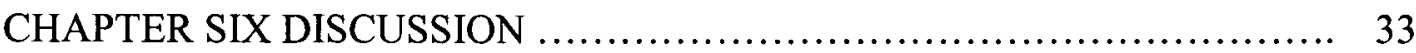

6.1 GOLD NANOPARTICLES CHARACTERIZATION .................... 33

6.2 AGAROSE GEL ELECTROPHORESIS .................................. 33

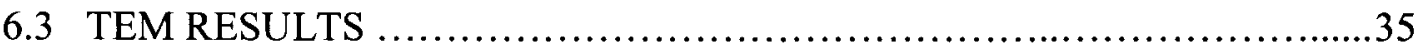

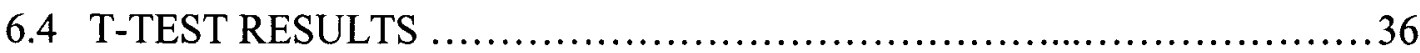

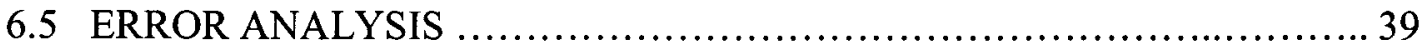

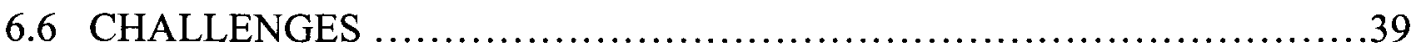

CHAPTER SEVEN CONCLUSIONS .................................... 41

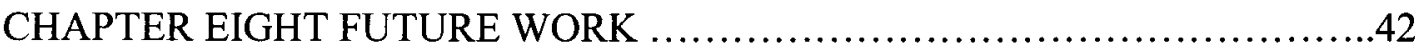

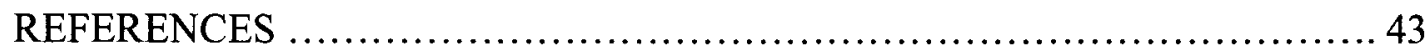


List of Figures

Figure 1. Peptide Synthesis from Amino Acids

Figure 2. Typically only 2 out of 4 binding sites on streptavidin (SAv) are occupied by biotin

Figure 3. Different orientation of crystals formed at different $\mathrm{pH}$ conditions.

(A) $\mathrm{P} 1$ lattice formed at $\mathrm{pH}<4.5$. (B) $\mathrm{C} 222$ lattice formed at $\mathrm{pH}>8$.

(C) P2 lattice formed at $\mathrm{pH} 5-6$ 3

Figure 4. (a) S-layer protein crystal on EM grid with gold coating. (b) Gold nanoparticles array, distance and position restricted by S-layer protein molecule

Figure 5. (a) $5 \mathrm{~nm}$ gold particles bound within the $3 \mathrm{~nm}$ pores of engineered chaperonin. (b) $10 \mathrm{~nm}$ gold particles binding within the $9 \mathrm{~nm}$ pores of engineered chaperonin

Figure 6. (A) Streptavidin molecules reorient themselves and are attracted towards the biotinylated lipid layer. (B) SAv bound to biotin forming crystals...... 8

Figure 7. Gold nanoparticle can bind to the 2 free unbound sites on streptavidin ..... 9

Figure 8. Gel electrophoresis results show that the bands correspond to a gold nanoparticle bound to a different numbers of DNA strands

Figure 9. TEM images of (a) QD-(Au) $)_{1}$ (b) QD-(Au) $)_{2}$ (c) QD-(Au).

(d) QD-(Au) 4

Figure 10. Overview of experimental procedure

Figure 11. Sample Gel electrophoresis set up .19

Figure 12. Procedure to extract band onto filter paper 20 
Figure 13. Teflon block set up

Figure 14. Two dimensional crystallization set up ............................ 21

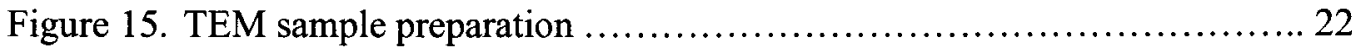

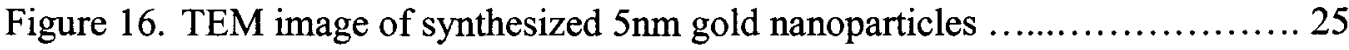

Figure 17. UV-Visible Spectrum of synthesized 5nm gold nanoparticles ........... 26

Figure 18. Gold nanoparticles Streptavidin binding stability test result. The pure Au turned bluish color while the SAv-Au remained reddish color 27

Figure 19. Result of test gel in determination of best Au:SAv ratio 28

Figure 20. Gel electrophoresis result. Lane 1: Free Au; Lane 2: SAv-Au (unbound SAv centrifuged away)

Figure 21. Absorbance spectrum of SAv-Au conjugates 30

Figure 22. TEM images of (a) Control experiment (Au only), (b) 1SAv-1Au and (c) $2 \mathrm{SAv}-1 \mathrm{Au}$ 32 


\section{List of Tables}

Table 1. Preparation of streptavidin and gold nanoparticles conjugate in 1:1 - 3:1 ratio .......................................................... 18

Table 2. Sample well set up procedure ............................................ 21

Table 3. Preparation of $1 \mathrm{mg} / \mathrm{ml} \mathrm{10:1} \mathrm{DMPC:Biotinylated} \mathrm{Mixed} \mathrm{Lipid} \mathrm{................} 22$

Table 4. T-test result for Interparticle Distances of Control Vs 1SAv-1Au experiment

Table 5. T-test result for Interparticle Distances of Control Vs $2 \mathrm{SAv}-1 \mathrm{Au}$ experiment 38

Table 6. Statistic summary of experiment's repeatability 39 


\section{CHAPTER ONE}

INTRODUCTION

Recently there has been an increased interest in the fabrication of nanoscale structures for a new generation of electronic and optical devices. As print features get smaller, the chips produced have higher circuit density. In other words, the performance is greater, and it utilizes less space, which can dramatically improve the speed and memory capacity of computer systems. Yet, the ability to fabricate large periodic arrays of nanoscale sized particles has remained a challenge. The classic technique to make integrated circuits, Micro-Electro-Mechanical Systems (MEMS), biochips, and optical components is known as photolithography [1,2]. MEMS devices refer to mechanical components on the micrometer scale such as 3D lithographic features of various geometries. With the current technology, it is possible to make features that are $20 \mathrm{~nm}$ in size [3]. However, with the high demand and competition of faster and cheaper computers, the target features are $10 \mathrm{~nm}$ or below. Moreover, with the current microlithography technology, the cost of the litohographic tools, process materials, and environmental control are relatively high [4]. Hence, an economic and environmentally safe way of achieving this goal is needed. Fortunately, one of nature's powerful tools, the self assembly property, may prove to be exactly what is needed.

\subsection{Background}

Streptavidin (SAv) is a protein that self assembles robustly under a variety of conditions [5]. Proteins are one of the most important components of our bodies. They are complex, high molecular weight organic compounds that consists of amino acids 
joined by peptide bonds. Proteins are essential to the structure and function of all living cells and viruses, and many of them act as enzymes or subunits of enzymes. Figure 1 shows the formation of peptide bonds as a way of combining two amino acids into a polypeptide. When the chain consists of more than 50 amino acids, it is referred to as a protein.<smiles>[R]C(N)C(=O)O</smiles><smiles>[R]C([NH3+])C(=O)O</smiles><smiles>[R]C([NH3+])C(=O)NC([R2])C(=O)O</smiles>

Figure 1. Peptide Synthesis from Amino Acids.

In Figure 1, the $\mathrm{R}$ represents the amino acid side chain which can have a neutral, positive or negative charge. This property allows proteins to be purified and separated using gel electrophoresis [6], which is a major technique that will be utilized in this project. More detailed information will be given in the experimental section.

The typical size of a SAv molecule is around $5 \mathrm{~nm}$ and can be referred to as a nanoparticle, which is a microscopic particle whose size is in the nanometers range. Additionally, another type of nanoparticle, gold nanoparticles in the range of $5 \mathrm{~nm}$ to 20 $\mathrm{nm}$, will also be used in this project. With the coupling of SAv and gold nanoparticles, an ordered array can be achieved using the technique of two-dimensional protein crystallization.

\subsection{Two Dimensional Protein Crystallization}

Two-dimensional protein crystallization is a method commonly used by protein crystallographers to investigate protein-protein interactions. With the aid of appropriate 
lipids that form a monolayer at an air-water interface, two-dimensional protein crystals can be obtained [7]. A relatively cheap and convenient choice is SAv and biotinylated lipid, where SAv has a high binding infinity to biotin. Each SAv contains 4 biotin bidding sites although typically only 2 are occupied as shown in Figure 2. Figure 3 shows the possible crystal orientations obtained at different $\mathrm{pH}$ conditions.

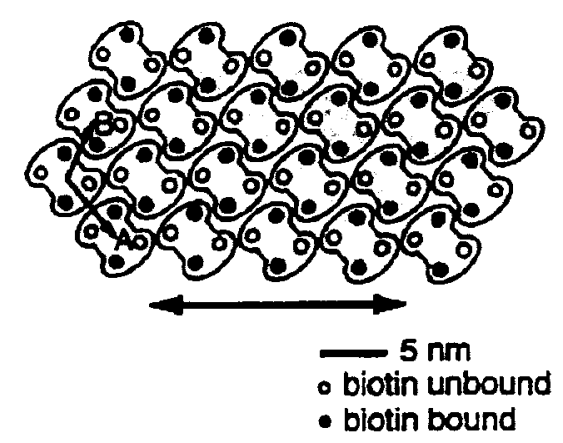

Figure 2. Typically only 2 out of 4 binding sites on streptavidin (SAv) are occupied by biotin [5].
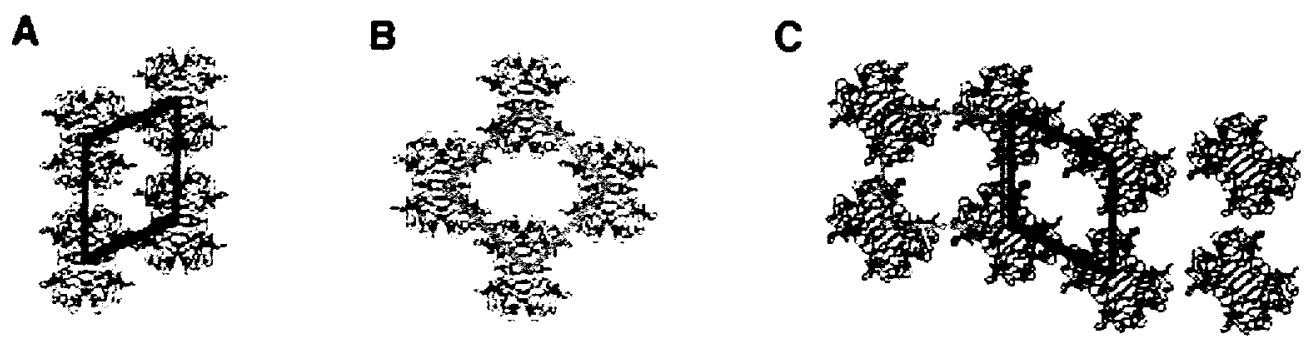

Figure 3. Different orientation of crystals formed at different $\mathrm{pH}$ conditions. (A) P1 lattice formed at $\mathrm{pH}<4.5$. (B) $\mathrm{C} 222$ lattice formed at $\mathrm{pH}>8$. (C) $\mathrm{P} 2$ lattice formed at $\mathrm{pH}$ $5-6[5]$.

Furthermore, SAv-biotin interactions have also been used for numerous biomedical and materials applications, and these molecules play a particularly useful role for the biomediated assembly of nanomaterials. With the use of a biotinylated lipid, twodimensional SAv crystals can be formed underneath the lipid surface. Research has been 
reported on the crystallization of SAv using the biotinylated lipid system, however, there is thus far no convincing article describing the use of such a system with gold nanoparticle. In this project, we propose the technique of growing two-dimensional crystals of SAv coupled with gold nanoparticles using the biotinylated lipid system formed at the air/water interface. Furthermore, we propose to vary the interparticle distances by controlling the number of SAv bound to the gold nanoparticles using gel electrophoresis.

\subsection{Significance}

With a different number of SAv moldcules attached to a gold nanoparticle, it may be possible to produce different feature size arrays that suit different applications. For instance, with the growing need for smaller feature size for chips productions, the ultimate goal is to make chips with the smallest feature size possible. Yet, certain applications, such as those used in conjunction with laser of various wavelengths, may be more sensitive than others; insufficient spacing between may cause interference. Thus it is important to develop a process that is flexible which can suit various applications with only slight modification. 


\section{CHAPTER TWO \\ LITERATURE REVIEW}

\section{$2.1 \quad$ S-Layer Protein Crystallization}

Because of their typical size, proteins are useful in many nanotechnology applications such as biosensors and computer chips because size is critical. In the past, the most commonly proteins used as vehicles for nanoparticle assembly have been bacterial cell membrane proteins (S-layer protein) and archaebacterial heat shock proteins (chaperonins) $[8,9]$. These proteins have demonstrated the ability to assemble spontaneously into well-ordered 2D arrays on silicon surfaces.

In 1997, Dieluweit and coworkers proposed a new strategy using bacterial cell surface layer (S-layer) protein as a template to fabricate ordered 4-5 nm gold particle arrays. In their paper, S-layer protein from Bacillus sphaericus CCM2177 was extracted and used in the recrystallization experiment on an electronic microscope grid. The microscope grid was then submerged into gold chloride solution $\left(\mathrm{HAuCl}_{4}\right)$ and analyzed by TEM. Analysis showed that the crystalline appeared to be gold crystals; frequently the particles were in a square shape and rotated by $45^{\circ}$ with respect to the base vectors of the S-layer lattice [8].

As shown in Figure 4 below, the gold nanoparticles only sit in the wells between each S-layer protein molecule, thus the distance between each gold nanoparticle is fixed at the dimension of each S-layer protein molecule. Also, the position of each gold nanoparticle is fixed and cannot be moved. 

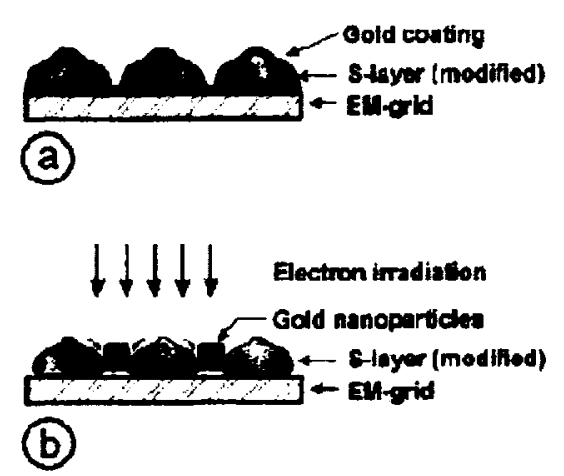

Figure 4. (a) S-layer protein crystal on EM grid with gold coating. (b) Gold nanoparticles array, distance and position restricted by S-layer protein molecule [8].

\subsection{Chaperonin Protein Crystallization}

An alternate of making data storage devices is from nanoscale arrays of quantum dots, which could hold enormous amounts of information. In 2002, McMillan et al. proposed to bind quantum dots onto protein templates of crystalline, geneticallyengineered chaperonins. Chaperonins are $16-18 \mathrm{~nm}$ in height and $15-17 \mathrm{~nm}$ in diameter and from hollow double-ring structures. The chaperonins were modified to contain either $3 \mathrm{~nm}$ or $9 \mathrm{~nm}$ apical pores surrounded by chemically reactive thiol groups, where the thiol groups were capable of binding with gold or quantum dots [10]. In addition, the modified chaperonins did not lose their ability to self-assemble, therefore, the orderly patterned chaperonins were able to bind to quantum dots and guide the alignment of quantum dots into ordered arrays, as shown in Figure 5 below. Like the S-layer protein technique, the quantum dots sit in the middle of the chaperonin protein molecule, and thus the position is fixed and not tunable. 


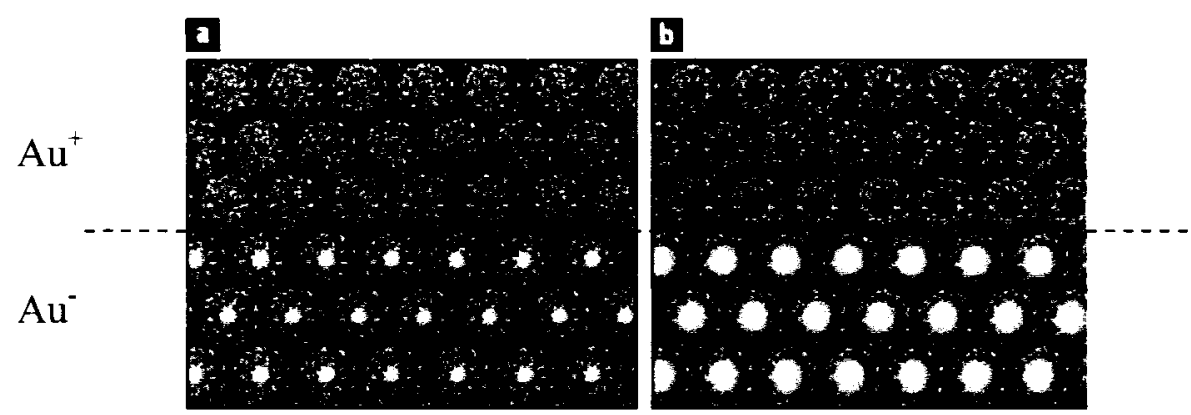

Figure 5. (a) $5 \mathrm{~nm}$ gold particles bound within the $3 \mathrm{~nm}$ pores of engineered chaperonin. (b) $10 \mathrm{~nm}$ gold particles binding within the $9 \mathrm{~nm}$ pores of engineered chaperonin [10].

\subsection{Streptavidin-Biotin System}

In 1991, Kornberg and Darst found that SAv crystallizes readily in two dimensions. They suggested that proteins bound to lipid layers form single-layer crystals and can be analyzed by electron microscopy and image processing. The method using lipids in the crystallization step is termed Lipid Layer Crystallization (LLC). Using LLC is advantageous because it depends on specific protein-ligand interactions, and such binding results in a high protein concentration at the lipid layer surface without loss of lateral mobility in the plane of the layer $[11,12]$. In particular, researchers chose to focus on was the SAv-biotin system. SAv has a very high affinity for biotin, and the interaction remains stable even at high temperature and extreme $\mathrm{pH}$ [13]. SAv can be coupled to a biotinylated lipid layer, in which SAv is the protein and biotin is the ligand. Analysis of the resulting crystals have showed diffraction to $2.8 \AA$ resolutions, indicating that order stability is comparable to that in three dimensions [12].

In 1989 Blankenburg et al. proposed the mechanism for formation of SAv-biotin crystals as shown in Figure 6 below. 
$\mathbf{A}$

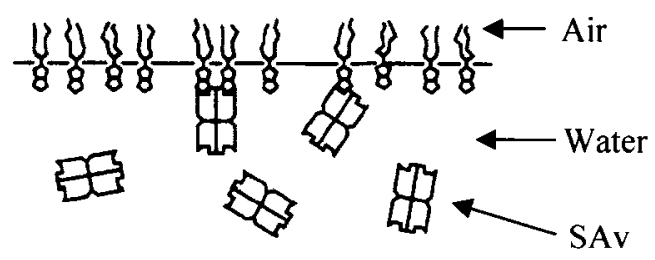

$$
\rrbracket
$$

B

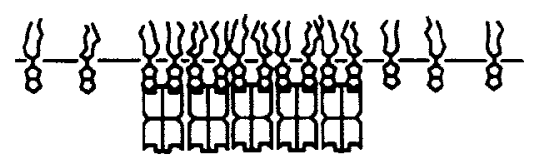

Figure 6. (A) Streptavidin molecules reorient themselves and are attracted towards the biotinylated lipid layer. (B) SAv bound to biotin forming crystals [14].

In their experiment, Blankenburg and coworkers attached a fluorescein molecule on one end of the SAv molecule. Then, making use of an air/water interface, $2 \mathrm{D}$ protein crystallization was carried out. As shown in Figure 6, the unique hydrophilic and hydrophobic properties allow the non-polar tail of the lipid to stand up in the air-face, while the polar heads remain in the aqueous solution. Biotin is bound to the polar head of the lipid system, thus, at the water-face, SAv molecules will orient themselves and form an attraction toward the biotinylated lipid. As a result SAv crystals are formed at the air/water interface. Analysis by electron microscopy confirmed the result of twodimensional crystal formation [14]. In addition, analysis showed that the only 2 sites on the SAv were bound. The other two showed fluorescence indicating they were not bound and were free and exposed to the aqueous solution. Similar results were confirmed by other research groups such as A. Brisson et al. in 1999 and W.R. Schief et al. in 1999 [15, 16]. 


\section{$2.4 \quad$ Streptavidin-Gold}

As was mentioned in section 2.2, there were two free sites available on the SAv after binding to biotin. As a result the two free sites are available for binding with other molecules such as fluorescein and gold nanoparticles. Figure 7 shows a schematic illustration of a gold nanoparticle binding to the free site end of a streptavidin molecule.

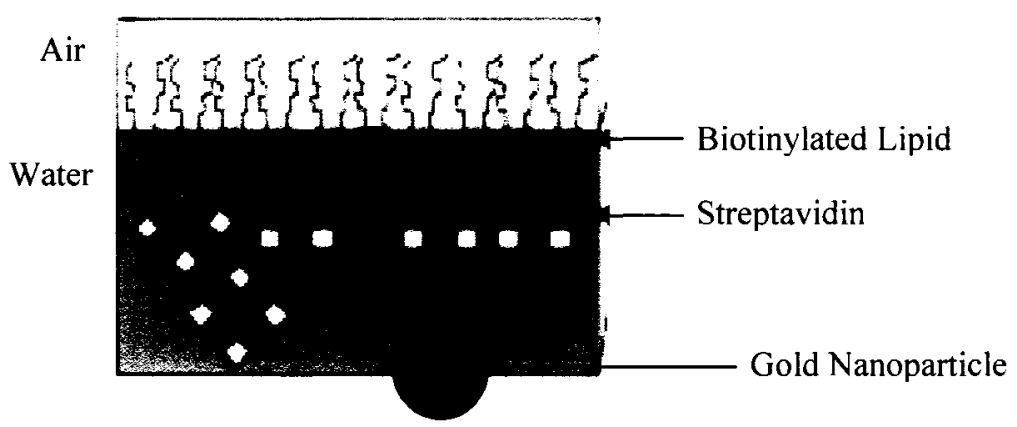

Figure 7. Gold nanoparticle can bind to the 2 free unbound sites on streptavidin [16].

According to Dykman et al. in 1996, SAv-gold conjugates were prepared by mixing the same ratio of each solution. The mixture was adjusted to $\mathrm{pH} 9-9.5$ and aggregation was determined by observing the color of the solution. A red solution indicates no aggregation, whereas a color of blue to purple indicates aggregation of the mixture. SAv-gold conjugates have been widely used in many experiments, and SAvgold conjugates are commercially available from many different chemical companies such as Sigma-Aldrich [17, 18, 19] and British BioCell International [20].

In 2001, Alexandre and co-workers made use of microarray as a powerful procedure and presented a new colorimetric detection method. By binding silver to gold nanoparticles, a signal was generated when the complex bound with streptavidin, and then to biotinylated DNA [21, 22]. Similarly, in 2004 Cai et al. reported an electrochemical methodology that enables the rapid identification of different DNA 
sequences on microfabricated electrodes. Electropolymerization of indium tin oxide (ITO) electrodes modified by the polymer scopoletin and embedded with streptavidin through selective immobilization of biotin-tagged probes allowed the selective immobilization of specific probe oligonucleotides. Their study demonstrated that the combination of the ability to selectively immobilize different oligonucleotide probes and a sensitive electrochemistry-based detection for multiple species is an important step forward for the realization of a portable bioanalytical microdevice for the rapid detection of pathogens [18].

In 2004, Sakihama and co-workers (2004) demonstrated that when zoospores were treated with the biotinylated photoaffinity probe and followed by UV irradiation and streptavidin-gold conjugate, probe-labeled proteins were detected on the cell membrane $[20]$.

All of the examples above show that streptavidin-gold conjugate is a widely used component in many experiments, and its commercial availability indicates that synthesis of such conjugates is a well known process.

\subsection{Sample Collection}

In 2000, Alivisato group at Berkeley demonstrated a method using gel electrophoresis to isolate $5 \mathrm{~nm}$ and $10 \mathrm{~nm}$ gold nanoparticle bound to discrete numbers of single-stranded DNA (1-5). By adjusting the DNA to Au ratio, they were able to control the average number of DNA strands per particle. Yet, due to the distribution of oligonucleotides present, the samples needed to be separated and isolated according to the number of strands bound per particle $[23,24]$. Gel electrophoresis is a technique 
widely used by scientists for separation of molecules based on size, net charge, or isoelectric point. Gel electrophoresis is driven by electromotive force (EMF) that pushes or pulls the molecules through a gel matrix. The molecules will move toward the gel at different rates when the molecules are placed in wells of a gel as an electric current is applied. The molecules will move toward the anode if negatively charged or toward the cathode if positively charged. In addition, smaller molecules will be moved toward the bottom of the gel faster than larger molecules [25].

Results showed that by doubling the ratio of DNA, the intensity of bands also varied. By increasing the DNA ratio, bands with more DNA strands bound to Au particles began to appear at the top, as illustrated in Figure 8.

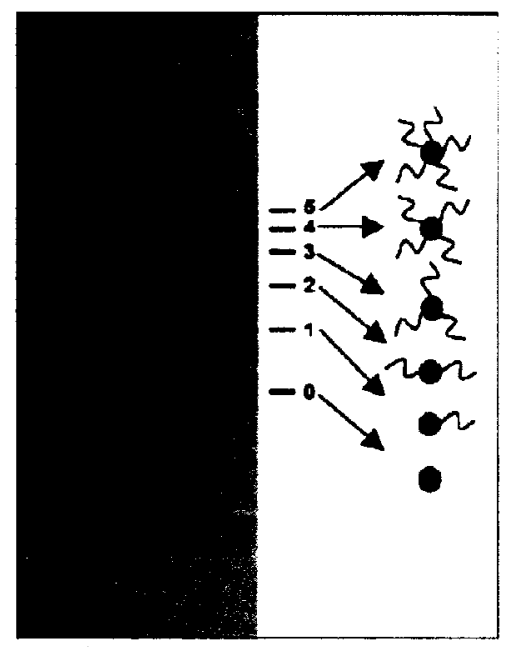

Figure 8. Gel electrophoresis results show that the bands correspond to a gold nanoparticle bound to a different numbers of DNA strands [23].

Alivisato and group in 2004, using the same approach, conjugated streptavidin coated quantum dots (QD) with gold nanoparticles. These discrete bioconjugated metal nanoparticles were eluted from the gel, where each distinct band contained purified samples of nanoparticle all possessing the same numbers of bound proteins. This 
separation method provided a well-defined set of bioconjugated building blocks for creating ordered nanoparticle arrays [23, 24]. Samples of each band were further analyzed using Transmission Electronic Microscopy (TEM), and results showed that the increasing spatial differences matched with increasing number of gold nanoparticles bound to a QD, as shown in Figure 9.

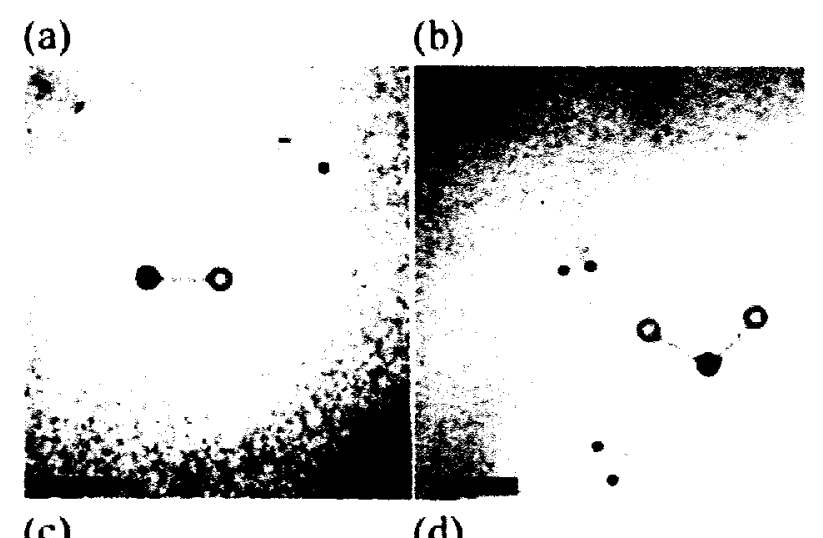

\section{(c)}

(d)

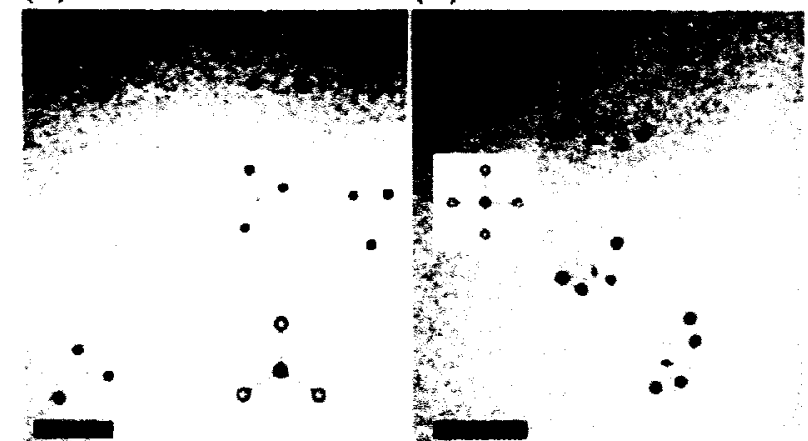

Figure 9. TEM images of (a) QD-(Au) . (b) QD-(Au) 2. (c) QD-(Au) $)_{3}$ (d) QD-(Au) 4 [26].

\subsection{Characterization}

Crystals formed at the air-water interface or on solid supports can be transferred to TEM grids for electron crystallographic analysis [27]. TEM is an imaging technique for which a beam of electrons is focused onto the sample causing an enlarged version to appear on a fluorescent screen or layer of photographic film, which can then be detected by a charged-couple device camera. In addition, low magnification of TEM worked well 
with particles in size of $15-30 \mathrm{~nm}$, whereas for smaller particles in range of 5-10 nm, high magnification is preferred [28].

\subsection{Summary}

Gold nanoparticles can be patterned with S-layer protein, yet the arrays will not be tunable. Streptavidin can form two dimensional crystals at an air/water interface, and it can be attached to metal nanoparticles. In addition, well defined SAv-Gold conjugates can be purified by gel electrophoresis, and the purified samples can be used for twodimensional protein crystallization. Streptavidin-Gold conjugates can be used to pattern tunable arrays, and the results can be analyzed by TEM. 


\section{CHAPTER THREE \\ RESEARCH HYPOTHESES}

The primary hypothesis of this study is that a gold nanoparticle arrays can be obtained by applying two dimensional protein crystallization techniques to gold nanoparticles and streptavidin conjugates. The secondary hypothesis is that there is a relationship between the number of streptavidin molecules bound to a single gold nanoparticle and the separation distance of gold nanoparticles on the array. In other words, by increasing the number of streptavidin molecules bound to a single gold nanoparticle, the interparticle distance between each gold nanoparticles will also increase.

Research results from the past have shown that the biotinylated lipid and streptavidin at the air/water interface is a robust system of protein crystallization. Since the gold nanoparticle is bound to the streptavidin electrostatically, there is no alteration of the streptavidin property. Thus gold nanoparticles bound to streptavidin theoretically will also form protein crystal at air/water interface with the aid of biotinylated lipid layer. In addition, to test these hypotheses, one of the objectives is to obtain a well-defined set of SAv-Au building blocks following the electrophoretic method developed by Alivisato and group in 2004. 


\section{CHAPTER FOUR \\ EXPERIMENTAL DESIGN AND APPARATUS}

The experimental procedure can be summarized into seven main steps as shown in Figure 10. First, gold nanoparticles obtained from IBM Almaden Research Center (ARC) was characterized using TEM to verify for correct particle size, and then using UV/Vis spectroscopy the concentration was be obtained. The next step was the binding of gold nanoparticles to streptavidin, followed by the separation and purification of the conjugate sample using gel electrophoresis. Then the gold nanoparticles/streptavidin conjugates was again characterized using UV/Vis spectroscopy to obtain the concentration. Thereafter, two dimensional protein crystallization/lipid assays was performed on a special built Teflon block with 48 wells. Lastly, the resulting protein crystal was analyzed using TEM.

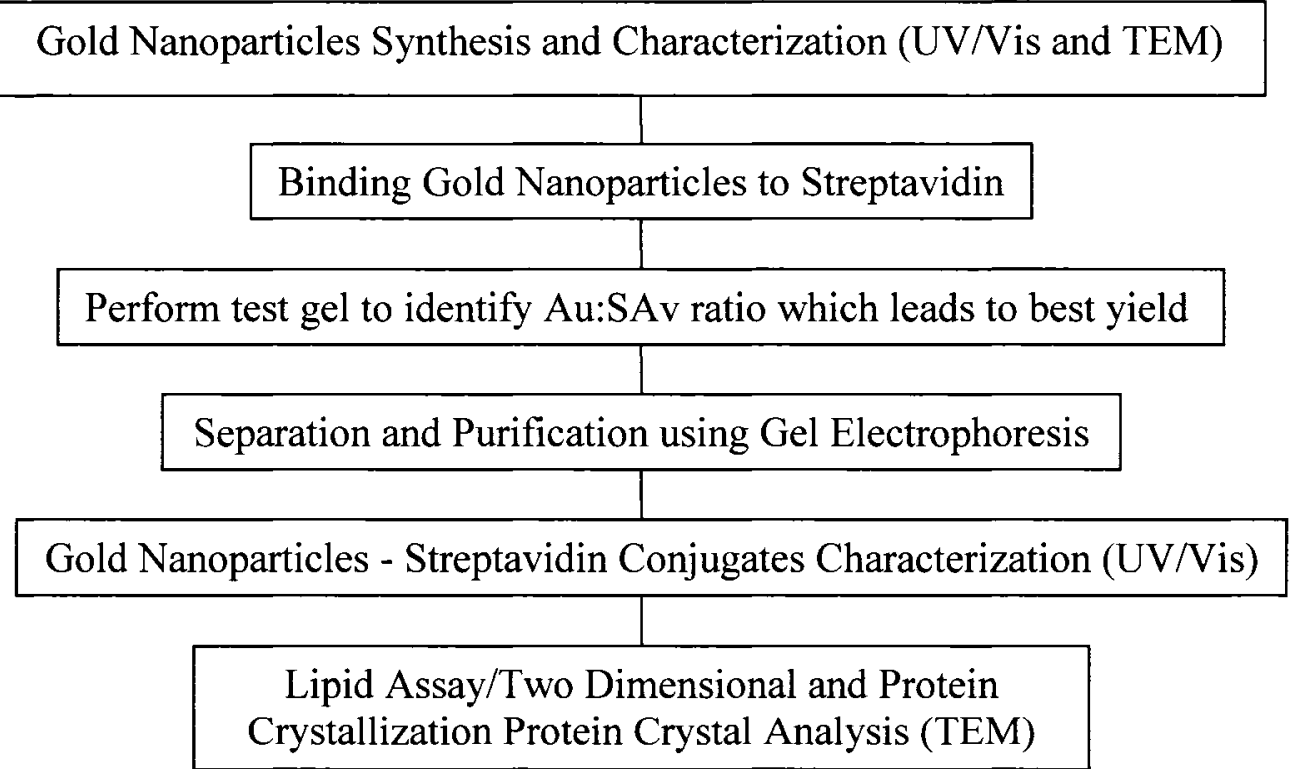

Figure 10. Overview of experimental procedure. 


\subsection{Gold Nanoparticles Synthesis}

The $5 \mathrm{~nm}$ gold nanoparticles used in this study were synthesized as part of the experiment in this thesis using a standard procedure from Electron Microscopy Science [29]. A $100 \mathrm{ml}$ aliquot of gold solution was made by preparing two separate solutions. In a round bottomed flask, solution A was prepared by adding $1 \mathrm{ml}$ of $1 \%$ gold chloride, $\mathrm{H}\left(\mathrm{AuCl}_{4}\right) \cdot \mathrm{H}_{2} \mathrm{O}$, to $79 \mathrm{ml}$ of deionized water. In an Erlenmeyer flask, solution B was prepared by mixing $4 \mathrm{ml} 1 \%$ sodium citrate, $1 \mathrm{ml} 1 \%$ tannic acid, $1 \mathrm{ml}$ potassium carbonate $\left(\mathrm{K}_{2} \mathrm{CO}_{3}\right)$ and $14 \mathrm{ml}$ of deionized water. Both solution $\mathrm{A}$ and $\mathrm{B}$ were heated on heat plates, when both solution reached $60^{\circ} \mathrm{C}$ solution $\mathrm{B}$ were added quickly to solution A. The combined solution was then kept stirring and heating 2-5 minutes after the temperature reached $100^{\circ} \mathrm{C}$. The solution was then removed from heat and cooled to room temperature. At this point, a drop of gold solution was dropped onto a TEM grid and let dry, and then it was analyzed using TEM for its particle size.

Then $30 \mathrm{mg}$ of phosphine was added to the solution and was incubated overnight. The next day, sodium chloride was added to the solution while stirring until the color turned blue. Thereafter, the gold solution was transferred into two $50 \mathrm{ml}$ centrifugal tubes, and centrifuged for 30 minutes at $4000 \mathrm{rpm}$. The supernatant was carefully removed, and the precipitate was resuspended using $200 \mu$ of deionized water. The gold sample was then transferred to a $1.5 \mathrm{ml} \mathrm{30K}$ Eppendorf filtered tube and centrifuged at $4000 \mathrm{rpm}$ for 25 minutes. Then $200 \mu$ l of deionized water was added to the pellet and centrifuged at $4000 \mathrm{rpm}$ for 25 minutes. The pellet was then resuspended using $200 \mu \mathrm{l}$ of 
deionized water and transferred into a new Eppendorf tube. This concentrated gold sample was then analyzed by UV-Visible spectroscopy for its concentration.

\subsection{Gold Nanoparticles Characterization}

The synthesized gold nanoparticles were characterized for their particle sizes using TEM. The desired particle size for this experiment was $4-5 \mathrm{~nm}$ which was selected base on the size of a SAv molecule. Then the absorbance of the gold nanoparticle solution was measured by Agilent 8453 UV-Visible Spectroscopy System, using the absorbance vs. wavelength plot generated by the UV/Vis software, the absorbance at 520 nm was identified, in conjunction of the Beer's Law, shown in Equation 1, the concentration of the solution was obtained:

$$
A=\varepsilon l c
$$

Equation 1

where $A$ is the absorbance (between $0.1-1.0$ ) measured at $520 \mathrm{~nm}, \varepsilon$ is the extinction coefficient of the $5 \mathrm{~nm}$ gold nanoparticles $\left(5.12 \times 10^{6} \mathrm{~L} / \mathrm{mol} \cdot \mathrm{cm}\right)$ obtained from the literature [30], $l$ is the path length fixed at $1 \mathrm{~cm}$, and $c$ is the concentration.

\subsection{Conjugation of Gold Nanoparticles with Streptavidin}

The TEM-characterized gold nanoparticles was mixed with streptavidin obtained from IBM ARC in 3 different SAv:Au ratios: 1:1, 2:1 and 3:1, as suggested by Alivisato and co-workers in 2001 when performing a similar type of experiment using DNA and gold nanoparticles [25]. The recipe is shown in Table 1. 
Table 1. Preparation of streptavidin and gold nanoparticles conjugates in 1:1-3:1 ratio.

\begin{tabular}{|l|l|l|l|l|}
\hline $\begin{array}{l}\text { SAv: } \mathrm{Au} \\
\text { Ratio }\end{array}$ & $\begin{array}{l}\text { Au }(5 \mathrm{mM} \text { working } \\
\text { condition) }\end{array}$ & $\begin{array}{l}\mathrm{SAv}(33.33 \\
\mathrm{mM})\end{array}$ & Distilled Water & $\begin{array}{l}\text { Total } \\
\text { Volume }\end{array}$ \\
\hline $0: 1$ & $\begin{array}{l}\text { Varies according to } \\
\text { concentration }\end{array}$ & $0 \mu \mathrm{l}$ & Add up to $20 \mu \mathrm{l}$ & $20 \mu \mathrm{l}$ \\
\hline $1: 1$ & $\begin{array}{l}\text { Varies according to } \\
\text { concentration }\end{array}$ & $3 \mu \mathrm{l}$ & Add up to $20 \mu \mathrm{l}$ & $20 \mu \mathrm{l}$ \\
\hline $2: 1$ & $\begin{array}{l}\text { Varies according to } \\
\text { concentration }\end{array}$ & $6 \mu \mathrm{l}$ & Add up to $20 \mu \mathrm{l}$ & $20 \mu \mathrm{l}$ \\
\hline $3: 1$ & $\begin{array}{l}\text { Varies according to } \\
\text { concentration }\end{array}$ & $9 \mu \mathrm{l}$ & Add up to $20 \mu \mathrm{l}$ & $20 \mu \mathrm{l}$ \\
\hline
\end{tabular}

\subsection{Gel Electrophoresis}

First, a test gel was performed. Each ratio of gold nanoparticles and streptavidin conjugate was tested using gel electrophoresis, and pure gold nanoparticles were used as the control. A 3\% agarose gel was utilized and run under the condition of $120 \mathrm{~V}$ for 90 minutes using BIO-RAD Power-Pac Basic. Gel electrophoresis was used because the electromotive force generated by the electric current moved the molecules through the gel matrix. Since gold nanoparticles are red pigmented, the bands are visible to the naked eye even under regular incident light, and separation of the bands can be observed as the electrophoresis proceeds. Then the lane with the clearest and most pigmented band (most yield) was identified as shown in Figure 11. 


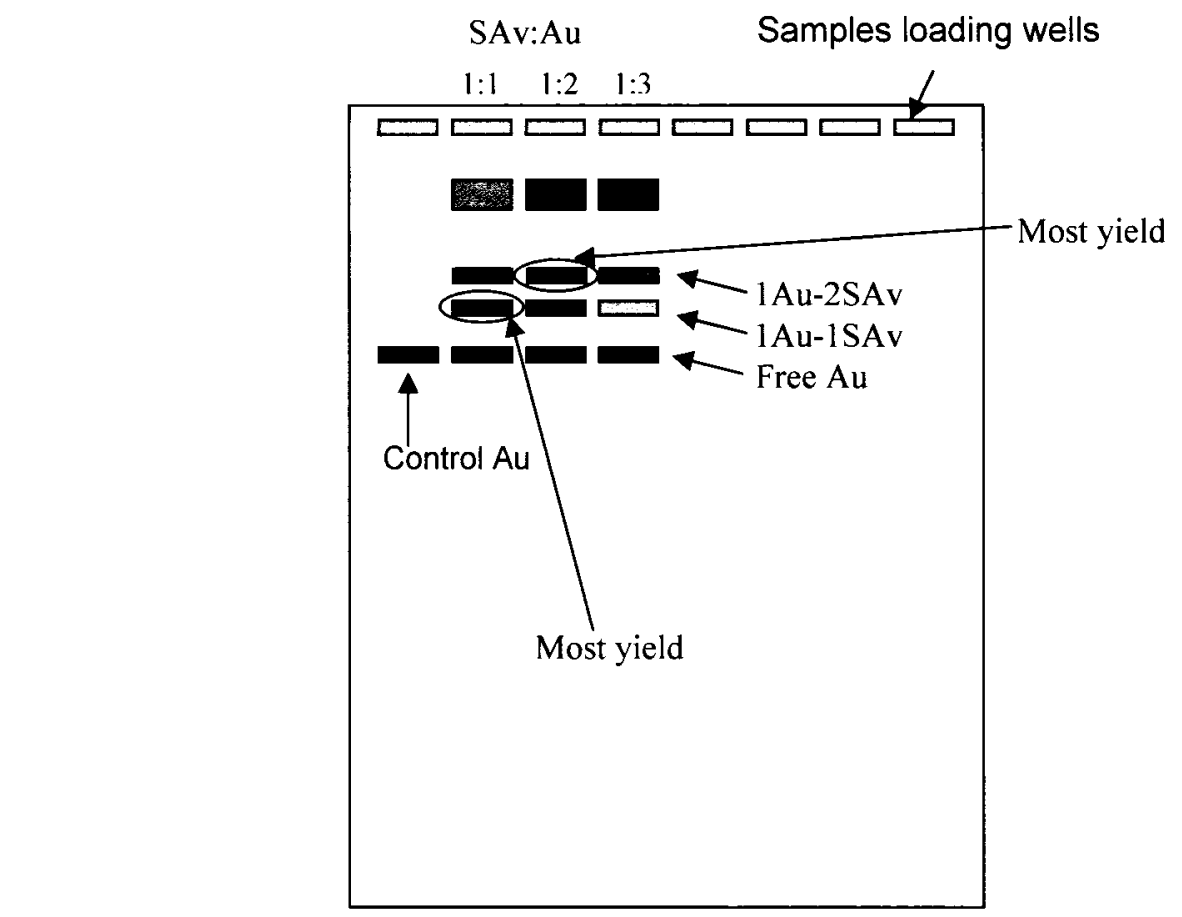

Figure 11. Sample Gel electrophoresis set up.

Next, the procedure described in section 4.2 was repeated using the ratio associated with the best yield ratio identified from the test gel. Desired sample bands were extracted from the gel using filter paper and dialysis tubing as shown in Figure 14. When the bands were well separated $(\sim 1 \mathrm{~cm}$ apart), electrophoresis was stopped and the gel was removed from the gel tray and the gel was slit below the desired band in order to insert an appropriately-sized piece of filter paper and dialysis as shown in Figure 12. Then the gel was put back onto the gel tray and the gel was ran under $120 \mathrm{~V}$ for another 10 minutes or until the entire band was collected onto the filter paper. As a side note, the purpose of the filter was to collect the desired band, and the dialysis tubing acted as a second filter to prevent any sample lost. After electrophoresis was completed, the filter paper was removed from the slit, put into $0.45 \mu \mathrm{m}$ centrifuge tube, and $20 \mu \mathrm{l}$ of water was added. The resulting solution was centrifuged using a Beckman Avanti 30 Centrifuge at 
$4000 \mathrm{rpm}$ for 15 minutes. The supernatant was then stored in an Eppendorf tube and characterized by UV/Vis Spectrometry.
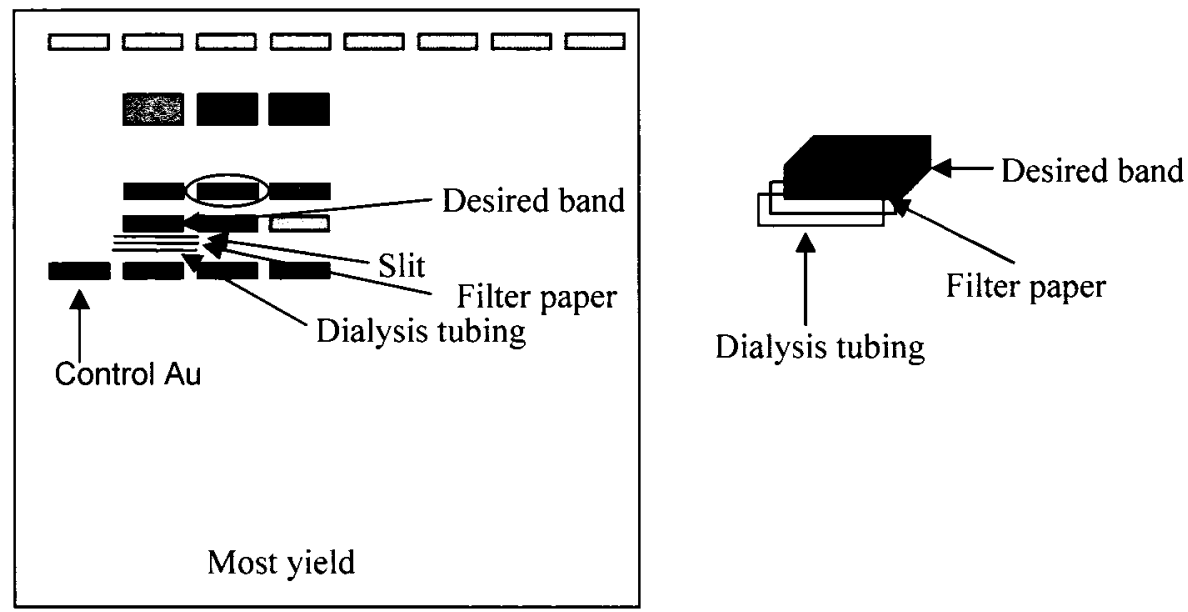

Figure 12. Procedure to extract band onto filter paper.

\subsection{Two-Dimensional Protein Crystallization}

This part of the project made use of a specially built Teflon block with 48 wells on the top face as shown in Figure 13. There was an injection port beside each well that could hold around $35 \mu \mathrm{l}$ of solution. For each set of experiments, 4 wells were used. In the four wells, water, sodium chloride $(\mathrm{NaCl})$, mixed lipid and Au-SAv sample were added in the proportion shown in Table 2 and calculation of each component was based on a final concentration of $150 \mathrm{mM} \mathrm{SAv}-\mathrm{Au}$. First water was added into each well, and then using a pipette, biotinylated lipid obtained from IBM ARC was added onto the water surface to allow formation of a lipid monolayer at air/water interface. Then the Au-SAv sample was injected underneath the water surface via the injection port using a syringe as shown in Figure 14. The reaction was allowed to proceed for 3 hours at room temperature inside a humidifying chambered filled with 50\% sodium chloride solution. 
The water level was maintained throughout the experiment by injecting additional water via the injection port every 30 minutes. The preparation of mixed lipid was listed in Table 3. Each set of experiments was to be repeated 3 times.

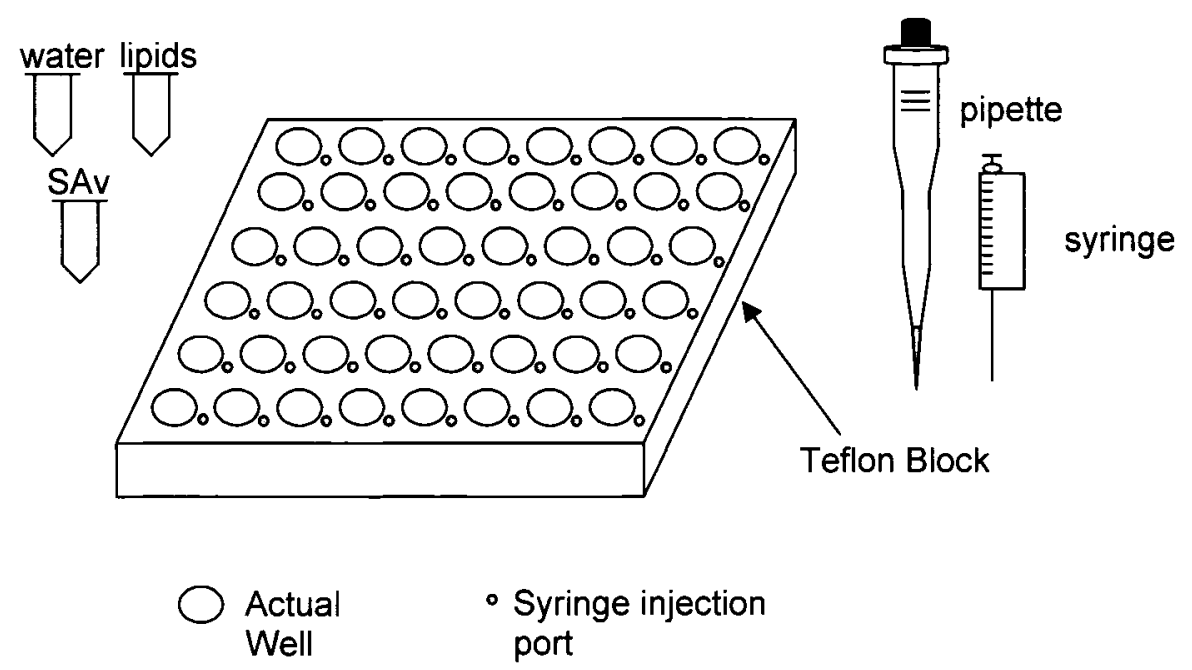

Figure 13. Teflon block set up.

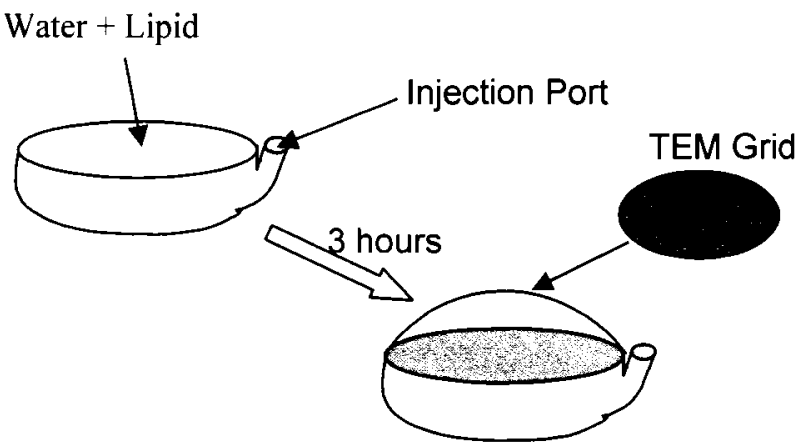

Figure 14. Two dimensional crystallization set up.

Table 2. Sample well set up procedure.

\begin{tabular}{|l|l|l|l|l|}
\hline Sample & Water & $1 \mathrm{M} \mathrm{NaCl}$ & Lipid System & Sample \\
\hline Pure $5 \mathrm{~nm} \mathrm{Au}$ & Add up to total $34 \mu \mathrm{l}$ & $3.4 \mu \mathrm{l}$ & $0.5 \mu$ l Mixed Lipid & Varies $0.1 \mu \mathrm{M}$ \\
\hline Pure $5 \mathrm{~nm} \mathrm{Au}$ & Add up to total $34 \mu \mathrm{l}$ & $3.4 \mu \mathrm{l}$ & $0.5 \mu$ l Mixed Lipid & Varies $0.2 \mu \mathrm{M}$ \\
\hline $1 \mathrm{Au}-1 \mathrm{SAv}$ & Add up to total $34 \mu \mathrm{l}$ & $3.4 \mu \mathrm{l}$ & $0.5 \mu$ l Mixed Lipid & Varies $0.2 \mu \mathrm{M}$ \\
\hline $1 \mathrm{Au}-2 \mathrm{SAv}$ & Add up to total $34 \mu \mathrm{l}$ & $3.4 \mu \mathrm{l}$ & $0.5 \mu$ l Mixed Lipid & Varies $0.1 \mu \mathrm{M}$ \\
\hline
\end{tabular}


Table 3. Preparation of $1 \mathrm{mg} / \mathrm{ml}$ 10:1 DMPC: Biotinylated Mixed Lipid.

\begin{tabular}{|l|l|l|l|}
\hline Compound & Ratio & Stock Concentration & Amount Used \\
\hline DMPC Lipid & 1 & $1 \mathrm{mg} / \mathrm{ml}$ & $5.00 \mu \mathrm{l}$ \\
\hline Biotinylated Lipid & 10 & $0.1 \mathrm{mg} / \mathrm{ml}$ & $8.40 \mu \mathrm{l}$ \\
\hline Chloroform & & & $36.60 \mu \mathrm{l}$ \\
\hline
\end{tabular}

\subsection{Analytical Sample Preparation}

The two dimensional protein crystals with gold nanoparticles attached were lifted up using the hydrophobic side of a carbon TEM grid as shown in Figure 15. The TEM grid was dropped onto the lipid surface and left for 10 second. Then the TEM grid was carefully lifted up and allowed to air dry.
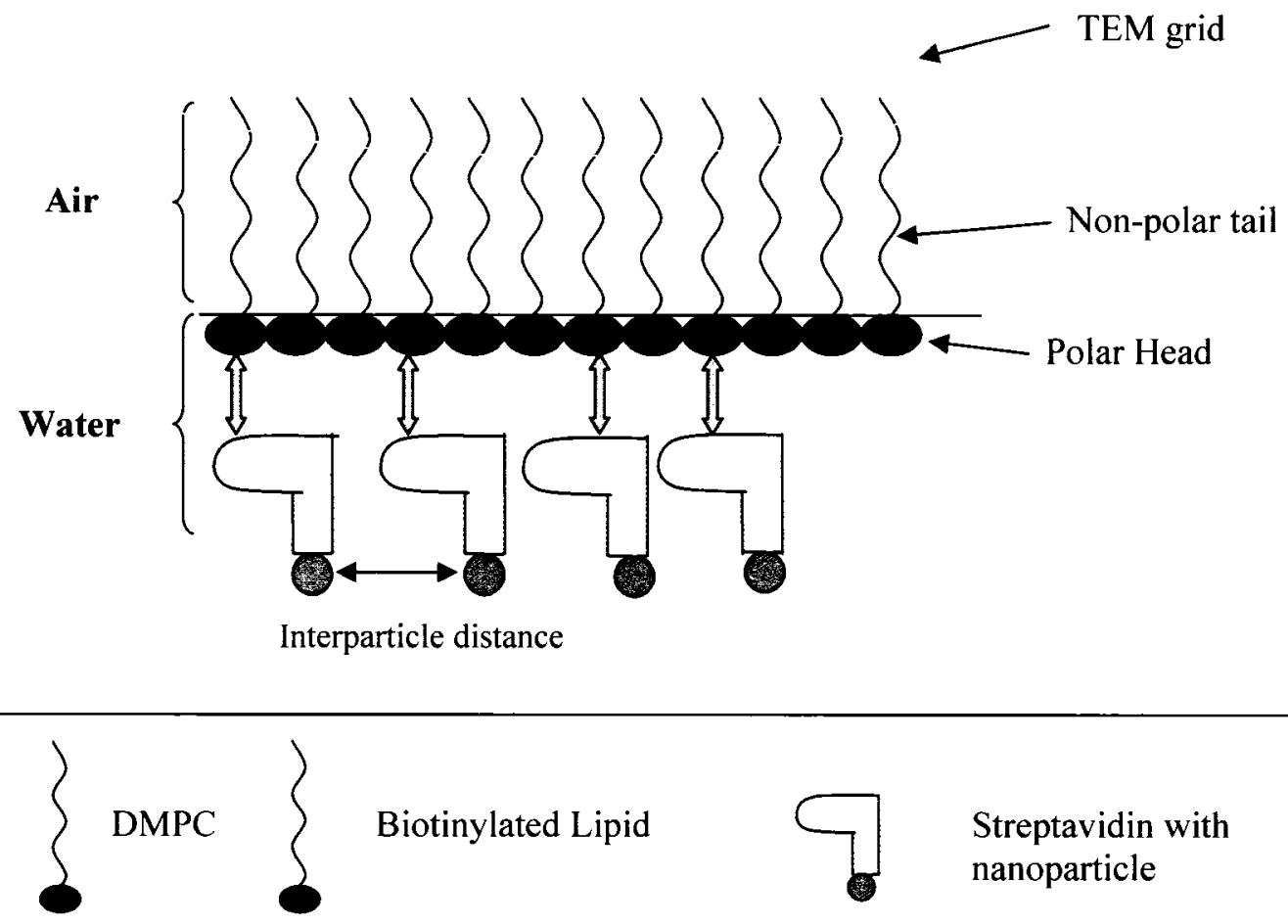

Figure 15. TEM sample preparation. 


\subsection{Transmission Electronic Microscopy (TEM)}

The two-dimensional protein crystals with gold nanoparticles attached was photographed by a transmission electronic microscope. Several photographs at different magnifications were taken for each sample.

\subsection{Data Analysis}

TEM photographs were analyzed and checked for specific binding between streptavidin and biotinylated lipid, in other words, to verify if there was any specific pattern generated. Then the interparticle distance between each gold nanoparticle was measured using the standardized scale installed in the TEM system, and the results were compared between samples with different ratio of gold nanoparticles to streptavidin molecules. For each sample, the TEM image was obtained in a randomly selected area and the interparticle distances were recorded. Furthermore, a t-test was performed in order to verify if the interparticle distances obtained for each experiment were really different than the control. The variance of difference of the two means $\left(\sigma_{d}\right)$ and the actual $\mathrm{t}$-values were calculated. The actual $\mathrm{t}$-values were then compared to the $\mathrm{t}$-value on the $\mathrm{t}$ test table at $95 \%$ confidence level, i.e., $\mathrm{p}=0.05$. 


\section{CHAPTER FIVE \\ EXPERIMENTAL RESULTS}

\subsection{Gold Nanoparticles Characterization}

Synthesized gold nanoparticles were characterized using TEM and UV/Vis

Spectroscopy. The image of gold nanoparticles was captured using TEM and the internal scale showed that the average size was $5 \mathrm{~nm}$ in diameter as shown in Figure 16. The image was printed out on paper and using the internal scale as reference, the sizes of 823 particles were measured by hand. The average size was calculated to be $5.27 \pm 0.96 \mathrm{~nm}$. Using the extinction coefficient at $520 \mathrm{~nm}$ [30] and absorbance value obtained from UV/Vis Spectroscopy results shown in Figure 17, the concentration was calculated by applying Beer's law. The $5 \mathrm{~nm}$ Au extinction coefficient was $5.12 \times 10^{6} \mathrm{~L} / \mathrm{mol} \cdot \mathrm{cm}$ and from Figure 17, it showed that the absorbance of the gold nanoparticles at $520 \mathrm{~nm}$ was 0.88, with 1:99 as dilution factor. Using Beer's law, the concentrations are calculated to be $1.72 \mu \mathrm{L}$. 


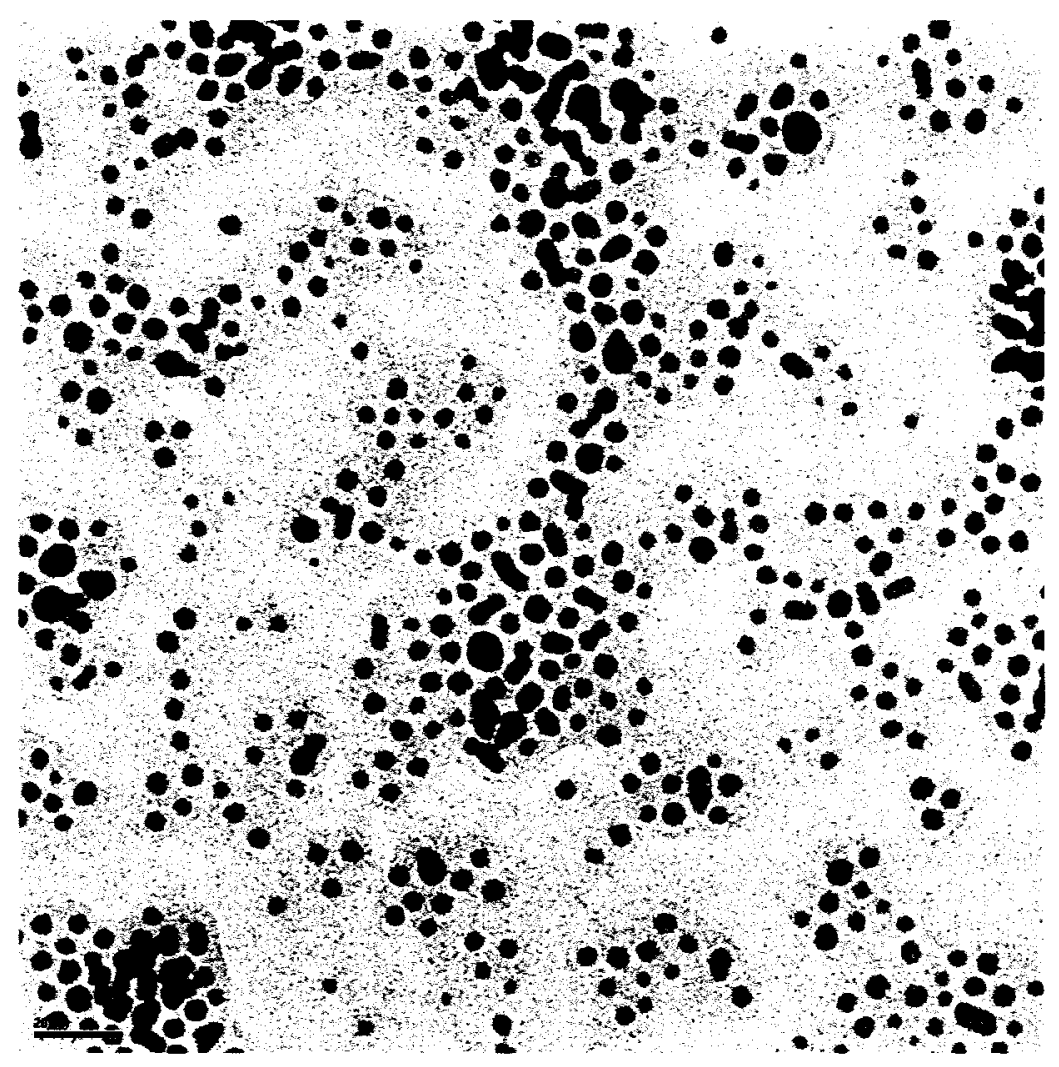

Figure 16. TEM image of synthesized 5nm gold nanoparticles. 
$5 \mathrm{~nm}$ Gold Nanoparticles Synthesis

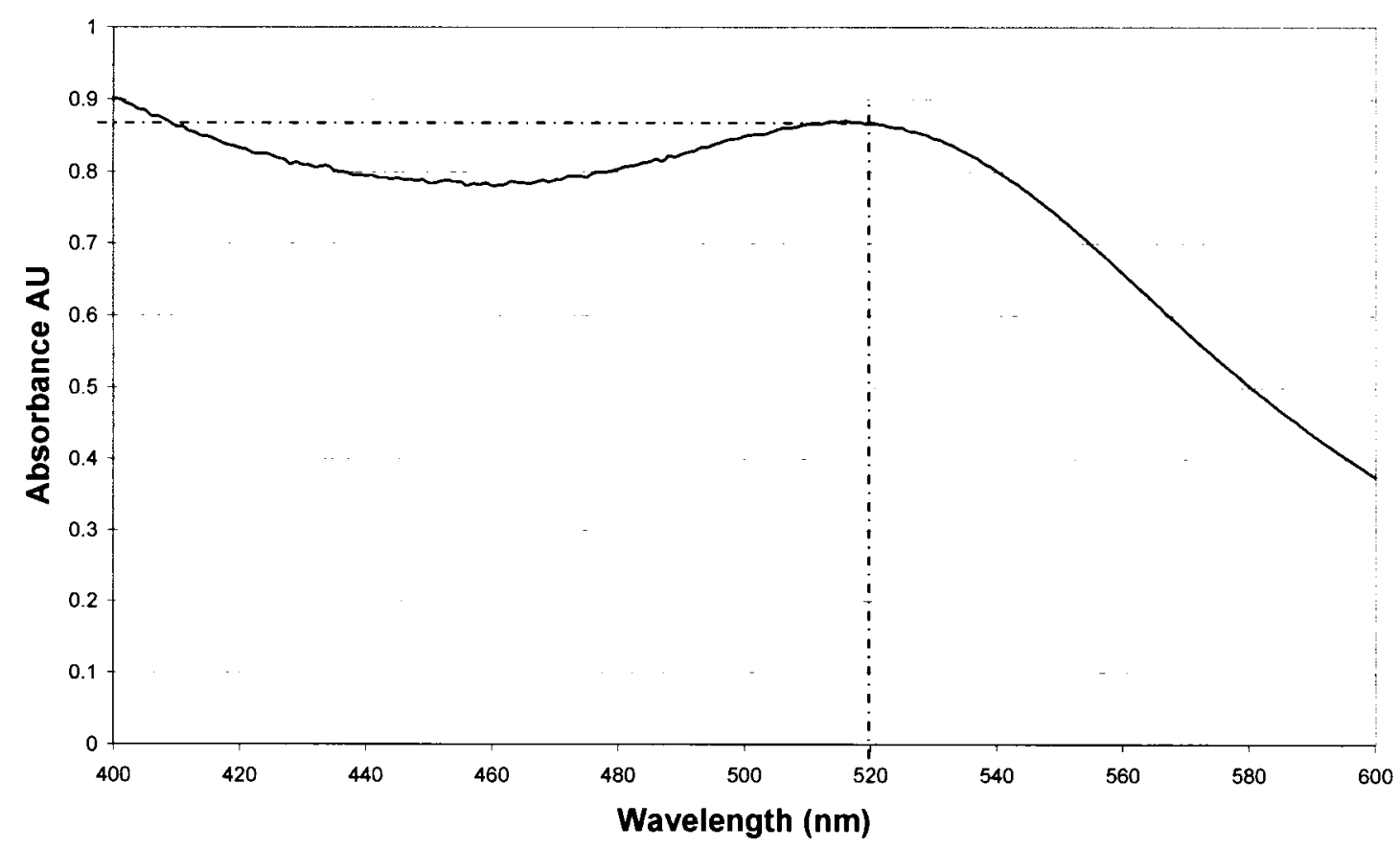

Figure 17. UV-Visible Spectrum of synthesized $5 \mathrm{~nm}$ gold nanoparticles.

\subsection{Binding Gold Nanoparticles to Streptavidin}

In order to visualize the red pigmented band on a $3 \%$ agarose gel, a working concentration of $5 \times 10^{6} \mathrm{M}$ of $5 \mathrm{~nm}$ gold nanoparticles was needed. Each well on the agarose gel could hold approximately $10 \mu \mathrm{L}$ of sample so the corresponding volume of gold nanoparticles required was calculated based on the required working concentration and the concentration obtained from the sample. Thereafter, three different molar ratios of streptavidin (1:1, 2:1 and 3:1) were mixed with the gold nanoparticle for 2 hours. The resulting binding efficiency was confirmed by performing an aggregation test. The control experiment was pure $5 \mathrm{~nm}$ gold nanoparticle, and the test was performed by adding $1 \mathrm{M}$ sodium chloride $(\mathrm{NaCl})$ to the $\mathrm{SAv}-\mathrm{Au}$ solution. Results showed that the 
control experiment of pure gold nanoparticles turned into a bluish color, indicating that aggregation has occurred. A reddish color was observed for the of SAv-Au solution indicating that gold was in the bound state A typical result of 2:1 SAv-Au versus pure gold nanoparticles is shown in Figure 18 below.

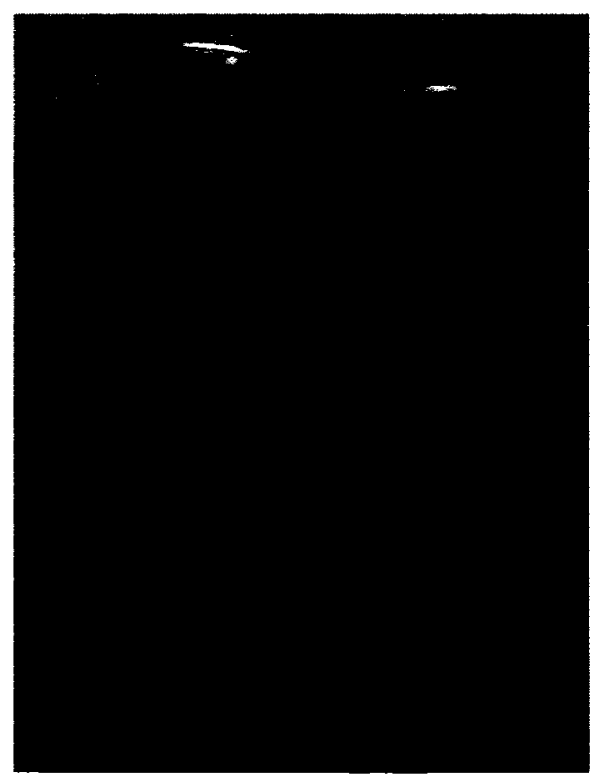

Figure 18. Gold nanoparticles Streptavidin binding stability test result. The pure Au turned bluish color while the SAv-Au remained reddish color.

\subsection{Gel Electrophoresis}

An initial test of gel electrophoresis was performed using 1:1, 2:1 and 3:1 molar ratio of SAv-Au to determine the best molar ratio with the highest yield. Gel electrophoresis was performed and as mentioned in section 4.3 , the most clear and pigmented band was chosen as the best ratio. The test gel result is shown in Figure 19, the first lane is free $5 \mathrm{~nm}$ gold nanoparticle, the second lane is $1: 1 \mathrm{SAv}-\mathrm{Au}$, the third lane is $2: 1 \mathrm{SAv}-\mathrm{Au}$ and the forth lane is $4: 1 \mathrm{SAv}-\mathrm{Au}$. The best ratio was determined to be $3: 1$ 
SAv-Au. This ratio was then used to prepare SAv-Au conjugate sample for the proceeding crystallization experiment.

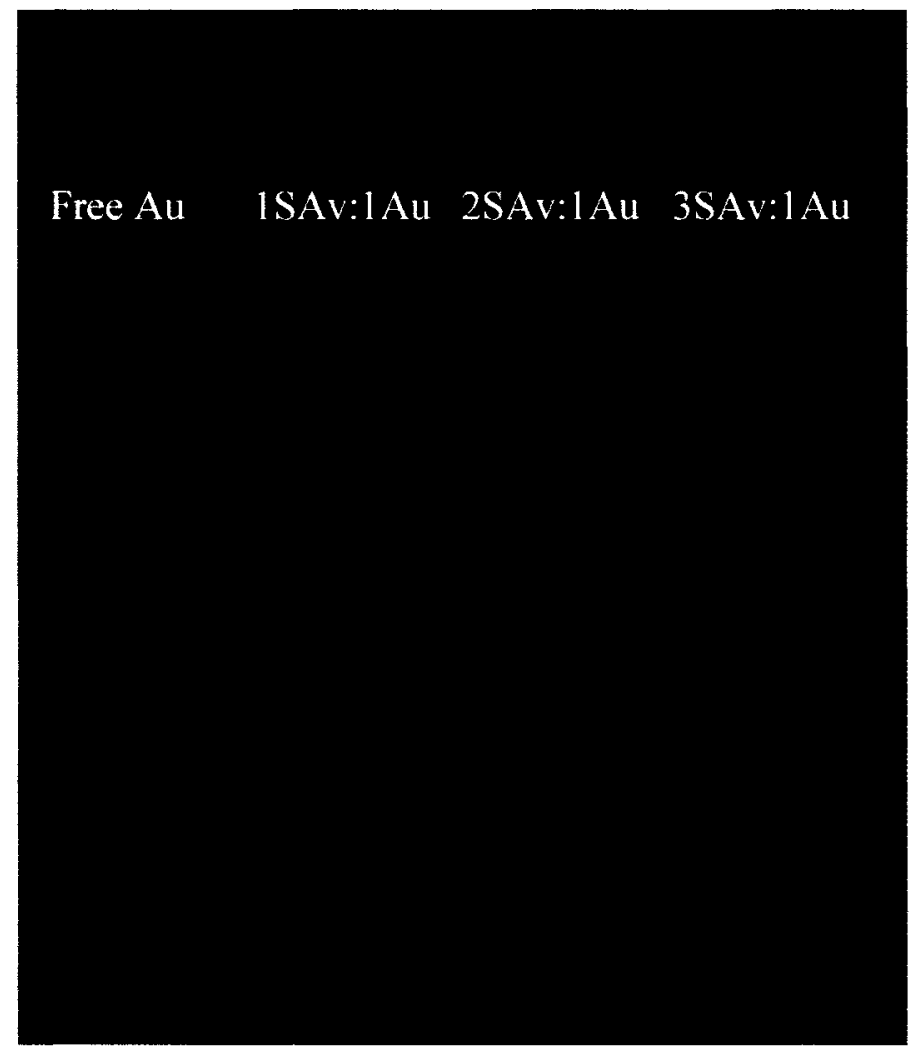

Figure 19. Result of test gel in determination of best Au:SAv ratio.

Based on those results, fifty seven $10 \mu \mathrm{L}$ aliquots of 3:1 SAv-Au conjugates were prepared in individual Eppendorf tubes. Three gels of nineteen samples were run on a 20 -well, $3 \%$ agarose gel along with one lane of pure $5 \mathrm{~nm}$ gold nanoparticles as a control. After 90 minutes the bands were extracted and stored as described in section 4.3. Samples from the three agarose gels were pooled together and concentrated down to 20 $\mu \mathrm{L}$ by centrifuging using $0.45 \mu \mathrm{m}$ Eppendorf filter tubes.

Figure 20 shows the gel electrophoresis results of the conjugated gold nanoparticles and streptavidin. Lane 1 shows the band of free gold nanoparticles, 
whereas Lane 2 shows the bands of various ratio of SAv-Au. At Lane 2, Band 1 represents 1SAv-1Au, Band 2 represents 2SAv-1Au, Band 3 represents 3SAv-1Au and Band 4 represents $4 \mathrm{SAv}-1 \mathrm{Au}$. The color of Band 1 appears to be the darkest, indicating it has the highest yields. In other words, most conjugation took place with $1 \mathrm{Au}$ and $1 \mathrm{SAv}$. In addition, Band 2 appears to be the second highest yield. As seen in Figure the separation distance between Band 2, 3 and 4 are small, making the extraction very challenging. Thus, only Band 1 and 2 were extracted from the gel.

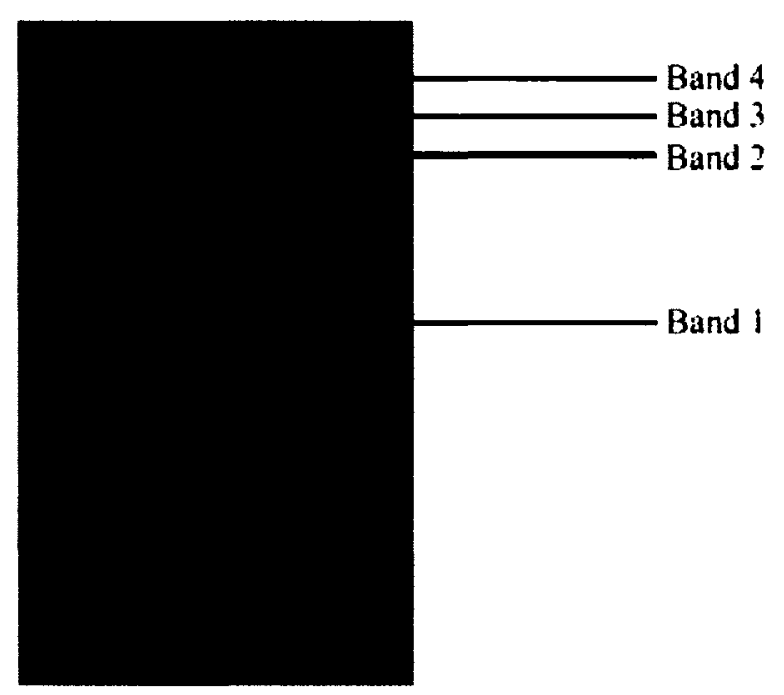

Figure 20. Gel electrophoresis result. Lane 1: Free Au; Lane 2: SAv-Au (unbound SAv centrifuged away).

After extraction from the agarose gel, the filter papers contained SAv-Au sample were put onto a Eppendorf filter tube containing a $30 \mathrm{~K}$ membrane.

\subsection{SAv-Au Conjugate Characterization}

Each SAv-Au conjugate was characterized using UV/Vis at $520 \mathrm{~nm}$. With the extinction coefficient of the $5 \mathrm{~nm}$ Au used, the concentration of SAv-Au conjugate 
sample obtained from the gel electrophoresis step was calculated using Beer's Law. The absorbance spectrum is shown in Figure 21.

\section{SAv-Au Conjugates UV/Vis Characterization}

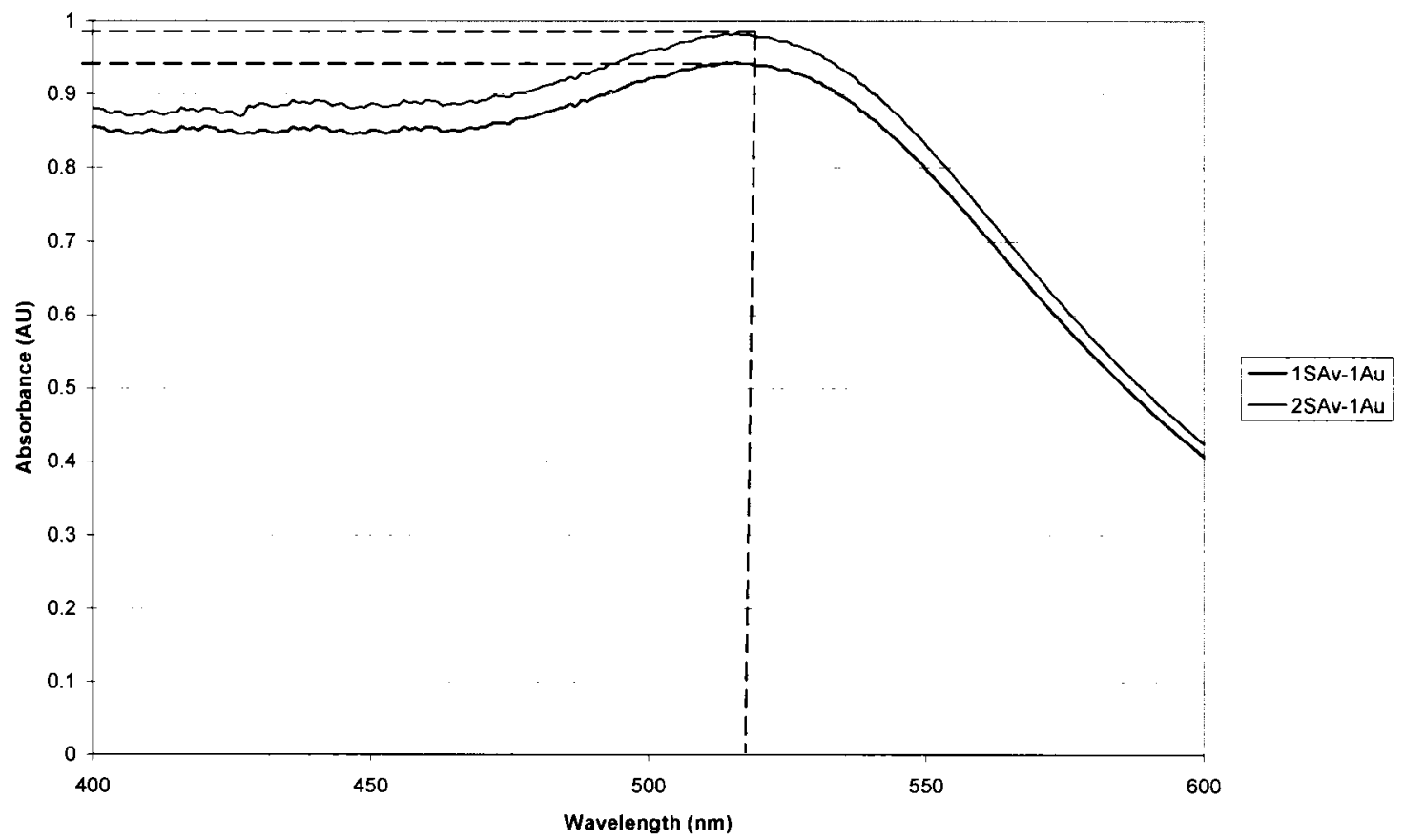

Figure 21. Absorbance spectrum of SAv-Au conjugates.

The $5 \mathrm{~nm} \mathrm{Au}$ extinction coefficient is $5.12 \times 10^{6} \mathrm{~L} / \mathrm{mol} \cdot \mathrm{cm}$ and from Figure 21, it shows that the absorbance of the 1SAv-1Au conjugate was 0.939 and 0.978 for $2 \mathrm{SAv}-$ 1Au conjugate, respectively, with 1:99 as dilution factor. Using Beer's law, the concentrations are calculated to be $1.85 \mu \mathrm{M}$ and $1.93 \mu \mathrm{M}$. The final SAv-Au conjugate concentration of $1 \mathrm{SAv}-1 \mathrm{Au}$ is $150 \mathrm{nM}$ where as $75 \mathrm{nM}$ for $2 \mathrm{SAv}-1 \mathrm{Au}$, therefore by calculation $2.76 \mu \mathrm{L}$ of sample was required for $1 \mathrm{SAv}-1 \mathrm{Au}$ experiment and $1.32 \mu \mathrm{L}$ for 2SAv-1 Au experiment. 


\subsection{TEM Images Results}

2D Protein crystallization was performed in the Teflon block inside a humidifying chamber as described in section 4.4. The lipid layer was lifted using the interaction of it with the hydrophobic carbon TEM grid. Once the lipid layer was contained on the grid it was analyzed by TEM. Figure 22 below shows TEM images of the control pure $5 \mathrm{~nm}$ gold nanoparticles, 1SAv-1 Au and 2SAv-1Au experiment, respectively. Comparing all 3 images visually, there is no distinct difference in the interparticle distance between the control and $1 \mathrm{SAv}-1 \mathrm{Au}$ experiment. In contrast, the interparticle distance of $2 \mathrm{SAv}-1 \mathrm{Au}$ experiment appears to be greater. To confirm the observation, a t-test was performed on the data. 


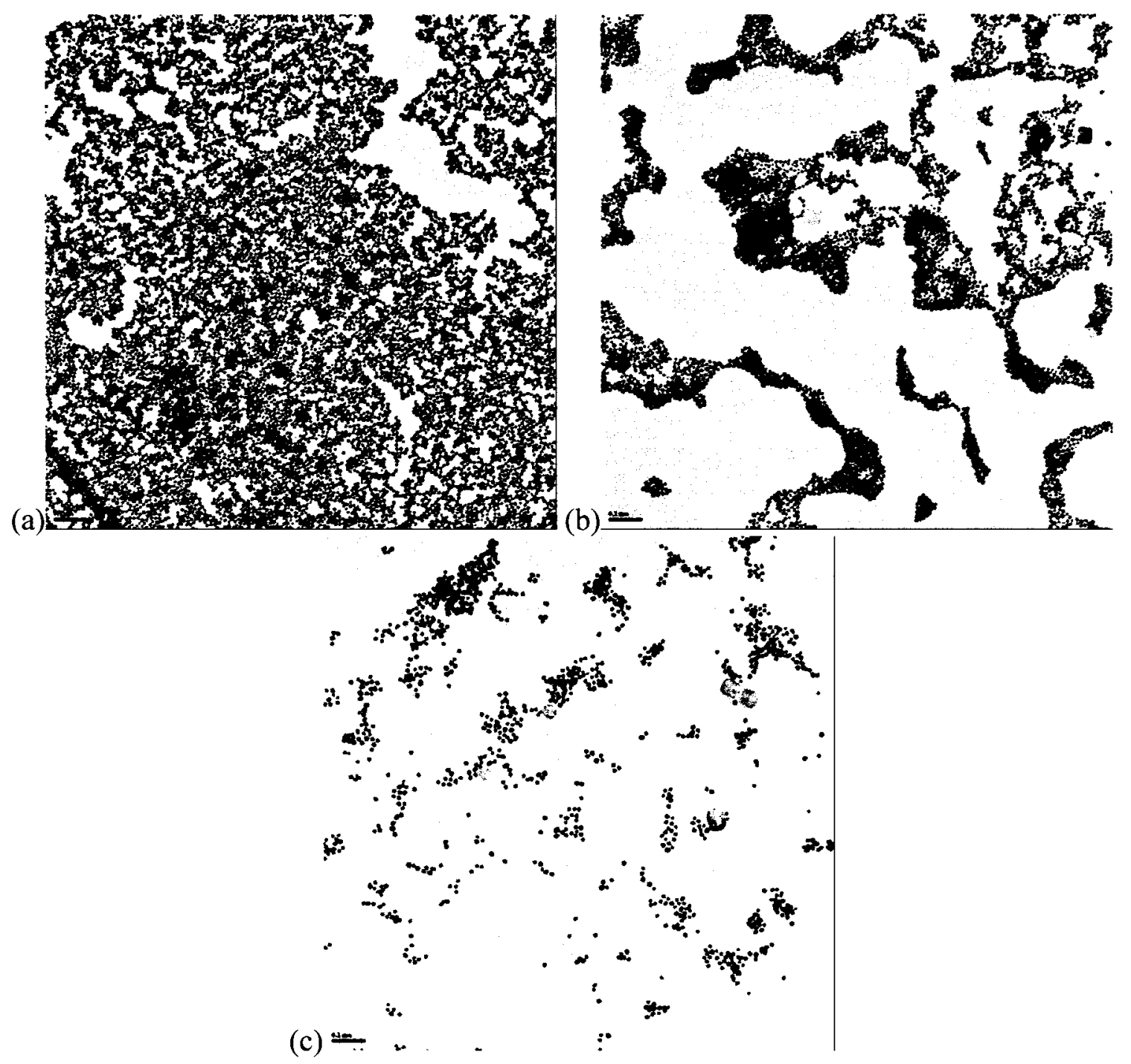

Figure 22. TEM images of (a) Control experiment (Au only), (b) 1SAv-1Au and (c) 2SAv-1Au. 


\subsection{Gold Nanoparticles Characterization}

With the internal scale set at $20 \mathrm{~nm}$, the TEM results from Figure 16 shows that the synthesized gold particles are in the range of $5-8 \mathrm{~nm}$. There is a distribution of particle size and overlapping of particles in some areas. The image was printed out on paper and using the internal scale as reference, the sizes of 823 particles were measured by hand. The average size was calculated to be $5.27 \pm 0.96 \mathrm{~nm}$. The overlapping of particles was possibly due to the process of sample preparation. The gold sample was dropped onto a TEM grid to air dry, before it was analyzed by TEM, and this drying process could lead to particles overlapping each other.

\subsection{Agarose Gel Electrophoresis}

A typical technique used in molecular biology and biochemistry to separate different sizes of proteins is Sodium Dodecyl Sulfate Polyacrylamide Gel Electrophoresis (SDS-PAGE). Due to a protein's natural folding property, proteins with similar molecular weight but different folded shapes would move through the porous gel matrix at different speeds. Sodium Dodecyl Sulfate denatures the secondary and tertiary structures of proteins, and this linearization allows the protein to separate strictly according to its molecular weight. Unfortunately this technique was not suitable for this project, as one of the objectives was to obtain nanoparticle array using $2 \mathrm{D}$ protein crystallization. By denaturing the Streptavidin, the crystallization would become impossible. 
Therefore, agarose gel electrophoresis, a commonly used separation technique for DNA and RNA, was used in place of SDS-PAGE in this project. Since the aim of gel electrophoresis in this project was to separate different sizes of Au-SAv conjugate, there was no other protein present and the use of agarose gel worked very well for this purpose.

As shown in Figure 19 and 20, the bands on the gel appeared to be red due to the color of the gold nanoparticles. This color was visible to the naked eye and greatly facilitated the extraction process. From Figure 19, the best ratio to be used for binding of streptavidin is 3:1 SAv-Au (Lane 3). The free gold band appears to be the least pigmented indicating that most gold particles were bound to streptavidin, and the second band and third band showed a decent yield compared to the remaining ratio. Although Band 1 in Lane 2 showed more pigmentation than Band 1 in Lane 4, there is no defined Band 2 observed in Lane 2. Due to economical reasons, Lane 4 was then picked as the best ratio so that using a single ratio of SAv:Au, the samples for setting up the experiment for 1SAv-1 Au and 2SAv-1Au could be obtained.

In Figure 20, Lane 1 showed the band of free gold nanoparticle, where as Lane 2 showed the bands for the conjugated gold nanoparticles to various number of streptavidin. Notice that the bands at Lane 2 were shifted upward compared to the free gold band at Lane 1, indicating that all the gold nanoparticles had been conjugated to streptavidin and there was no free gold nanoparticle present. In addition to the shifting at Lane 2, a difference in band height was also observed. The height of the first band was greater than the proceeding bands, which was evidence that the first band could possibly consist of more than one band. The merging of bands could be due to a similar migration rate 
and smearing of the bands leading to unclear boundary of the band. Yet, this problem would not affect the objective of this project, since the proceeding bands still represented a greater number of SAv conjugated to Au compared to the first band.

The first band extracted from the gel was referred to as $1 \mathrm{SAv}-1 \mathrm{Au}$, and the second band was referred to as $2 \mathrm{SAv}-1 \mathrm{Au}$. The proceeding bands were not extracted as the separation distance between band 2 and band 3,4 were too close and extraction was very difficult.

It should be noted that a test gel was performed at the $120 \mathrm{~V}$ for 120 minutes, but the bands appeared to be very smear and faint, thus this condition was not utilized in the study. No test gel was studied in which alternating the voltage was performed.

\subsection{TEM Results}

Other than the TEM analysis of the synthesized gold nanoparticles, TEM images with the same resolution were obtained for the control, $1 \mathrm{SAv}-1 \mathrm{Au}$ and $2 \mathrm{SAv}-1 \mathrm{Au}$ experiments. As shown in Figure 17, the control experiment showed larger particle coverage in the same area than $1 \mathrm{SAv}-1 \mathrm{Au}$ and $2 \mathrm{SAv}-1 \mathrm{Au}$. In other words, the presence of streptavidin increased the spacing between the gold nanoparticles. It should be noted that there was less particle overlap for the $1 \mathrm{SAv}-1 \mathrm{Au}$ and $2 \mathrm{SAv}-1 \mathrm{Au}$ experiments than the control, indicating that the conjugation of gold nanoparticles to streptavidin did not alter streptavidin's crystallization property, and this property could be useful in generating nanoparticle arrays. In addition, the particle coverage of $1 \mathrm{SAv}-1 \mathrm{Au}$ was greater than $2 \mathrm{SAv}-1 \mathrm{Au}$, indicating that an increased number of bound streptavidin also increased the spacing between gold nanoparticles. However these interpretations were 
based on inspection by naked eye, thus t-tests were performed to give statistical support to the observations.

\section{$6.4 \quad$ T-Test Results}

The student t-test was performed on the data sets of the control, 1SAv-1Au and $2 \mathrm{SAv}-1 \mathrm{Au}$ experiments. The purpose of the test was to verify the null hypothesis that the mean of the two sample sets are equal. At $95 \%$ confident level and infinity degrees of freedom $\left(n_{1}+n_{2}-2\right)$, the calculated t-value was compared to the tabulated t-value. If the calculated t-value was greater than the tabulated $t$-value, the difference between the means of the two sets of data was statistically different.

Table 4 shows the t-test results comparing the interparticle distances for the control and 1SAv-1Au experiment. As shown in Table 4 below, the calculated t-value is less than the tabulated t-value with $\mathrm{p}=0.05$. In other words, at $95 \%$ level of confidence the interparticle distances of the control experiment is not significantly different from 1SAv-1Au experiment. 
Table 4. T-test result for Interparticle Distances of Control Vs 1SAv-1 Au experiment.

\begin{tabular}{|c|c|c|}
\hline Parameter & Control & $1 \mathrm{SAv}-1 \mathrm{Au}$ \\
\hline $\mathrm{n}$ & 5031 & 2159 \\
\hline$\sum x$ & 12390 & 4988 \\
\hline$\sum x^{2}$ & 53747 & 3485 \\
\hline$\left(\sum x\right)^{2}$ & $2.531 \mathrm{E} 7$ & $2.484 \mathrm{E} 7$ \\
\hline$\frac{\left(\sum x\right)^{2}}{n}$ & 5031 & 11526 \\
\hline$\Sigma d^{2}$ & 48716 & 23331 \\
\hline$\sigma^{2}$ & 9.68 & 10.81 \\
\hline$\sigma d^{2}-\begin{array}{l}\sigma_{1}^{2} \\
\mathrm{n} 1\end{array}+\begin{array}{l}\sigma_{2}^{2} \\
\mathrm{n} \geqslant\end{array}$ & & 0.00693 \\
\hline$\sigma_{d}$ & & 0.08326 \\
\hline$t=\frac{\bar{x}_{1}-\bar{x}_{2}}{t \bar{d}}$ & & 1.83 \\
\hline Tabulated $t$-value $(\mathrm{p}=0.05)$ & & 1.96 \\
\hline
\end{tabular}

Table 5 shows the t-test results comparing the interparticle distances for the control and 2SAv-1Au experiment. As shown in Table 5 below, the calculated t-value is greater than the tabulated $\mathrm{t}$-value with $\mathrm{p}=0.05$. In other words, at $95 \%$ confident level, the interparticle distances of the control experiment is significantly different from the 2SAv-1Au experiment. 
Table 5. T-test result for Interparticle Distances of Control Vs 1SAv-1Au experiment.

\begin{tabular}{|l|l|l|}
\hline Parameter & Control & $2 \mathrm{SAv}-1 \mathrm{Au}$ \\
\hline $\mathrm{n}$ & 5031 & 796 \\
\hline$\sum x$ & 12390 & 5080 \\
\hline$\sum x^{2}$ & 53747 & 56003 \\
\hline$\left(\sum x\right)^{2}$ & $2.531 \mathrm{E} 7$ & $2.580 \mathrm{E} 7$ \\
\hline$\frac{\left(\sum x\right)^{2}}{n}$ & 5031 & 32420 \\
\hline$\sum d^{2}$ & 48716 & 23583 \\
\hline$\sigma^{2}$ & 9.68 & 29.67 \\
\hline$\sigma d^{2}-\sigma_{1}^{2}+\sigma_{2}^{2}$ \\
\hline$\left.\sigma_{d}\right)$ & & 0.0392 \\
\hline$t=\frac{\bar{x} 1^{-}-\bar{x} 2}{c z d}$ & & 0.198 \\
\hline Tabulated t-value (p=0.05) & & 19.8 \\
\hline
\end{tabular}

As shown in Table 4, the calculated t-value of 1.83 was less than the tabulated $t-$ value of 1.96. Hence, the means between the data sets obtained from the control and 1SAv-1 Au experiment were not significantly different at $95 \%$ confident level. In other words, statistically the interparticle distances of the control experiment were not significantly different from the interparticle distances of the 1SAv-1Au experiment.

As shown in Table 5, the calculated t-value of 19.8 was greater than the tabulated $\mathrm{t}$-value of 1.96 . Thus, at $95 \%$ confident level, the means between the data sets of control and $2 \mathrm{SAv}-1 \mathrm{Au}$ were significantly different. In other words, the interparticle distances of the $2 \mathrm{SAv}-1 \mathrm{Au}$ were significantly different than the interparticle distances of the control experiment. 


\subsection{Error Analysis}

The $2 \mathrm{D}$ protein crystallization experiment was repeated 3 times at the same condition. The TEM images obtained showed consistency of the results. Although the TEM images in Figure 17 showed one section of TEM grid, it was a good representation of the overall image obtained at lower resolution. The repeatability was good since the 3 sets of experiment performed on different days yield similar results as shown in Table 6 . Table 6. Statistic summary of experiment's repeatability.

\begin{tabular}{|l|l|l|l|}
\hline Experiment & Set Number & Average $(\mathrm{nm})$ & Combined Average $(\mathrm{nm})$ \\
\hline Control & 1 & 2.63 & \\
\hline & 2 & 2.37 & \\
\hline & 3 & 2.39 & $\mathbf{2 . 4 6} \pm \mathbf{0 . 1 4}$ \\
\hline $1 \mathrm{Au}-1 \mathrm{SAv}$ & 1 & 2.28 & \\
\hline & 2 & 2.24 & \\
\hline & 3 & 2.4 & $\mathbf{2 . 3 1} \pm \mathbf{0 . 0 8}$ \\
\hline $1 \mathrm{Au}-2 \mathrm{SAv}$ & 1 & 5.64 & \\
\hline & 2 & 6.75 & \\
\hline & 3 & 6.75 & $\mathbf{6 . 3 8} \pm \mathbf{0 . 6 4}$ \\
\hline
\end{tabular}

\subsection{Challenges}

There were many challenges of each step of the process, from synthesizing gold nanoparticles to obtaining TEM images for the protein crystallization. Synthesis of each batch of nanoparticles is sufficient for running 1 agarose gel, thus in order to run 3 gels, 3 batches of gold nanoparticles had to be synthesized. Furthermore, the process of collecting SAv-Au samples was long and tedious. In order to obtained samples concentrated enough for the $2 \mathrm{D}$ protein crystallization experiment, samples were required to be collected from 3 agarose gels. It is possible that an experiment using the Langmuir trough could be performed to confirm the amount of SAv-Au samples required to obtain 
a monolayer in a specific area, unfortunately the large amount of SAv-Au sample required to run this experiment is not infeasible and thus this test was not performed. 
In this study, streptavidin was conjugated with gold nanoparticles using free gold nanoparticles as a reference. Purified samples of 1SAv-1Au and 2SAv-1Au were obtained from agarose gel electrophoresis. Results in this study showed that a discrete number of SAv bound to Au could be obtained through conjugation and gel electrophoresis, which were used as building blocks in the crystallization experiment.

TEM images were obtained from $2 \mathrm{D}$ protein crystallization experiments under the same resolution for the control, 1SAv-1Au and 2SAv-1Au experiments. Results showed that there was a significant visual difference between the control and $2 \mathrm{SAv}-1 \mathrm{Au}$ experiment in the area coverage as well as the interparticle distances, thus further confirmed that the conjugation of gold nanoparticles to streptavidin did not alter streptavidin's crystallization property, and this property could be useful in generating nanoparticle arrays.

Student t-test results confirmed that an increased number of streptavidin conjugated to gold nanoparticle could increase the gold nanoparticle interparticle distances in this study for $2 \mathrm{SAv}-1 \mathrm{Au}$, however not for $1 \mathrm{SAv}-1 \mathrm{Au}$. In conclusion, 2D protein crystallization using a lipid monolayer can be used to generate a gold nanoparticle array. 


\section{CHAPTER EIGHT}

FUTURE WORK

Using 2D protein crystallization to obtain nanoparticle arrays can significantly lower the production cost compared to photolithographic techniques. This study has set a start point for research in this area, however further investigation is needed. Future work could be done to verify the results from this study by using 3SAv-1Au samples. Also, characterization of the samples could be done to investigate the actual number of streptavidin bound to gold nanoparticles. Further research can be done on the absorbance property of Streptavidin and $5 \mathrm{~nm}$ gold nanoparticles. Absorbance can be taken by $\mathrm{UV} /$ Vis spectroscopy at $280 \mathrm{~nm}$ and $520 \mathrm{~nm}$ and analyzed the corresponding concentration of SAv and Au. Then the actual molar ratio and number of SAv per Au can be determined. 


\section{REFERENCES}

1 A.S. Blawas and W.M. Reichert, "Protein patterning," Biomaterials, 19, pp. 595-609 (1998).

2 C. Wang and M. Madou, "From MEMS to NEMS with carbon," Biosens. Bioelectron., 20, pp. 2181-2187 (2005).

3 S.S. Choi, M.Y. Jung, D.W. Kim, M.A. Yakshin, J.Y. Park, and Y. Kuk, "Fabrication of microelectron gun arrays using laser micromachining," Microelectron. Eng., 41/42, pp. 167-170 (1998).

4 S.V. Sreenivasan, C. Grant Willson and Douglas J. Resnick (2004). Small Print [Online]. Available at http://www.memagazine.org/contents/current/features/nanosmpr/nanosmpr.html (accessed 20 February 2005).

5 A.P. Gast, C.R. Robertson, S.W. Wang and M.T. Yatcilla, "Two-dimensional streptavidin crystals: macropatterns and micro-organization,” Biomol. Eng., 16, pp. 21-27 (1999).

6 J. Wales and L. Sanger (2001). Amino Acid [Online]. Available at http://en.wikipedia.org/wiki/Amino_acids (accessed 24 February 2005).

7 D. Levy, M. Chami and J.L. Rigaud, “Two-dimensional crystallization of membrane proteins: the lipid layer strategy," FEBS Lett., 504, pp. 187-193 (2001).

8 S. Dieluweit, D. Pum and U. B. Sleytr, "Formation of a gold superlattice on an Slayer with square lattice symmetry," Supramol. Sci., 5, pp. 15-19 (1998).

9 D.A. Haley, M.P. Bova, Q.L. Huang, H.S. Mchaourab and P.L. Stewart, "Small heatshock protein structures reveal a continuum from symmetric to variable assemblies," J. Mol. Biol., 298, pp. 261-272 (2000).

10 R.A. McMillan, C.D. Paavola, J. Howard, S.L. Chan, N.J. Zaluzec and J.D. Trent. "Ordered nanoparticle arrays formed on engineered chaperonin protein templates," Nat. Mater., 1, pp. 247-252 (2002).

11 R.D. Kornberg and S.A. Darst, "Two-dimensional crystals of proteins on lipid layers," Curr. Opin. Struct. Biol., 1, pp. 642-646 (1991). 
12 S.A. Darst, M.Ahlers, P.H. Meller, E.W. Kubalek, R. Blankenburg, H.O. Ribi, H. Ringsdorf and R.D. Kornberg, "Two-dimensional crystals of streptavidin on biotinylated lipid layers and their interactions with biotinylated macromolecules," Biophys. J., 59, pp. 387-96 (1991).

13 J. Wales and L. Sanger (2001). Biotinylation [Online]. Available at http://en.wikipedia.org/wiki/Biotinylation (accessed 20 February 2005).

14 R. Blankenburg, P. Meller, H. Ringsdorf and C. Salesse, "Interaction between biotin lipids and streptavidin in monolayers: formation of oriented two-dimensional protein domains induced by surface recognition," Biochemistry, 28, pp. 8214-8221 (1989).

15 A. Brisson, W. Bergsma-Schutter, F. Oling, O. Lambert and I. Reviakine, "Twodimensional crystallization of proteins on lipid monolayers at the airĐwater interface and transfer to an electron microscopy grid," J. Cryst. Growth, 196, pp. 456-470 (1999).

16 W.R. Schief, T. Edwards, W. Frey, S. Koppenol, P.S. Stayton and V. Vogel, "Twodimensional crystallization of streptavidin: in pursuit of the molecular origins of structure, morphology, and thermodynamics," Biomol. Eng., 16, pp. 29-38 (1999).

17 L. Nicu, M. Guirardel, F. Chambosse, P. Rougerie, S. Hinh, E. Trevisiol, J.M. Francois, J.P. Majoral, A.M. Caminade and E. Cattan, C. Bergaud, "Resonating piezoelectric membranes for microelectromechanically, based bioassay: detection of streptavidin-gold nanoparticles interaction with biotinylated DNA," Sens. Actuators B, In Press, (2005).

18 H. Cai, C. Shang and I.M. Hsing, "Sequence-specific electrochemical recognition of multiple species using nanoparticle labels," Anal. Chim. Acta, 523, pp. 61-68 (2004).

19 R.Q. Liang, C.Y. Tan and K.C. Ruan, "Colorimetric detection of protein microarrays based on nanogold probe coupled with silver enhancement," J. Immunol. Methods, 285, pp. 157-163 (2004).

20 Y. Sakihama, T. Shimai, M. Sakasai, T. Ito, Y. Fukushi, Y. Hashidoko and S. Tahara, "A photoaffinity probe designed for host-specific signal flavonoid receptors in phytopathogenic Peronosporomycete zoospores of Aphanomyces cochlioides," Arch. Biochem. Biophys., 432, pp. 145-151 (2004). 
21 I. Alexandre, S. Hamels, S. Dufour, J. Collet, N. Zammatteo and F. De Longueville, "Colorimetric silver detection of DNA microarrays," Anal. Biochem. 295, pp. 1-8 (2001).

22 M. Ji, P. Hou, S. Li, N. He and Z. Lu, "Colorimetric silver detection of methylation using DNA microarray coupled with linker-PCR," Clin. Chim. Acta, 342, pp. 145153 (2004).

23 D. Zanchet, C.M. Micheel, W.J. Parak, D. Gerion, and A.P. Alivisatos, "Electrophoretic Isolation of Discrete Au Nanocrystal/DNA Conjugates," Nano Lett. 1, pp. 32-35 (2001).

24 D. Zanchet, C.M. Micheel, W.J. Parak, D. Gerion, S.C. Williams and A.P. Alivisatos, "Electrophoretic and Structural Studies of DNA-Directed Au Nanoparticle Groupings," J. Phys. Chem. B, 106, pp. 11758-11763 (2002).

25 J. Wales and L. Sanger (2001). Gel Electrophoresis [Online]. Available at http://en.wikipedia.org/wiki/Gel_electrophoresis (accessed 2 March 2005).

26 A. Fu, C.M. Micheel, J. Cha, H. Chang, H. Yang and A.P. Alivisatos, "Discrete Nanostructures of Quantum Dots/Au with DNA," J. Am. Chem. Soc., 126, pp. 10832-10833 (2004).

27 C.J. Loweth, W.B. Caldwell, X.G. Peng, A.P. Alivisatos and P.G. Schultz, "DNAbased assembly of gold nanocrystals," Angew. Chem., Int. Ed., 38, pp. 1808-1812 (1999).

28 J. Wales and L. Sanger (2002). Transmission Electron Microscopy [Online]. Available at http://en.wikipedia.org/wiki/TEM (accessed 2 March 2005).

29 Electron Microscopy Science (2003). [Online]. Gold Solutions Preparation Technical Data Sheet. Available at https://www.emsdiasum.com/microscopy/technical/datasheet/gold_sols.aspx (accessed August 28th, 2006).

30 M.A. Carpenter (2003). Feasibility of a SOFC Stack Integrated Optical Chemical Sensor [Online]. Available at http://www.netl.doe.gov/publications/proceedings/03/ucr-hbcu/Carpenter.pdf (accessed April 23rd, 2006). 